\title{
Concepts and principles of photodynamic therapy as an alternative antifungal discovery platform
}

\section{Tianhong Dai ${ }^{1,2}$, Beth B. Fuchs ${ }^{3}$, Jeffrey J. Coleman ${ }^{3}$, Renato A. Prates ${ }^{4}{ }^{+}$, Christos Astrakas ${ }^{5}$, Tyler G. St. Denis ${ }^{1,6}$, Martha S. Ribeiro ${ }^{4}$, Eleftherios Mylonakis ${ }^{3}$, Michael R. Hamblin $^{1,2,7}$ and George P. Tegos ${ }^{1,2,8,9}$ *}

${ }^{1}$ Wellman Center for Photomedicine, Massachusetts General Hospital, Boston, MA, USA

${ }^{2}$ Department of Dermatology, Harvard Medical School, Boston, MA, USA

${ }^{3}$ Division of Infectious Diseases, Massachusetts General Hospital, Boston, MA, USA

${ }^{4}$ Center for Lasers and Applications, IPEN-CNEN/SP, São Paulo, São Paulo, Brazil

${ }^{5}$ Division of Internal Medicine, Democritus University of Thrace Medical School, Alexandroupolis, Greece

${ }^{6}$ Department of Chemistry, Columbia University, New York, NY, USA

7 Harvard-MIT Division of Health Sciences and Technology, Cambridge, MA, USA

${ }^{8}$ Center for Molecular Discovery, University of New Mexico, Albuquerque, NM, USA

${ }^{9}$ Department of Pathology, University of New Mexico School of Medicine, Albuquerque, NM, USA

\section{Edited by:}

Bruce C. Campbell, Western Regional

Research Centre, USA

\section{Reviewed by:}

Paul Cos, Antwerp University, Belgium

Simon Andrew Johnston, University of Birmingham, UK

\section{*Correspondence:}

George P. Tegos, Department of Pathology, School of Medicine,

Center for Molecular Discovery, UNM Health Sciences Center, University of New Mexico, 2325 Camino de Salud, CRF 217A MSC 07-4025

Albuquerque, NM 87131, USA.

e-mail: gtegos@salud.unm.edu

\section{${ }^{\dagger}$ Present address:}

Renato A. Prates, School of Dentistry, University Nove de Julho (UNINOVE), São Paulo, São Paulo, Brazil.
Opportunistic fungal pathogens may cause superficial or serious invasive infections, especially in immunocompromised and debilitated patients. Invasive mycoses represent an exponentially growing threat for human health due to a combination of slow diagnosis and the existence of relatively few classes of available and effective antifungal drugs. Therefore systemic fungal infections result in high attributable mortality. There is an urgent need to pursue and deploy novel and effective alternative antifungal countermeasures. Photodynamic therapy (PDT) was established as a successful modality for malignancies and age-related macular degeneration but photodynamic inactivation has only recently been intensively investigated as an alternative antimicrobial discovery and development platform. The concept of photodynamic inactivation requires microbial exposure to either exogenous or endogenous photosensitizer molecules, followed by visible light energy, typically wavelengths in the red/near infrared region that cause the excitation of the photosensitizers resulting in the production of singlet oxygen and other reactive oxygen species that react with intracellular components, and consequently produce cell inactivation and death. Antifungal PDT is an area of increasing interest, as research is advancing (i) to identify the photochemical and photophysical mechanisms involved in photoinactivation; (ii) to develop potent and clinically compatible photosensitizers; (iii) to understand how photoinactivation is affected by key microbial phenotypic elements multidrug resistance and efflux, virulence and pathogenesis determinants, and formation of biofilms; (iv) to explore novel photosensitizer delivery platforms; and (v) to identify photoinactivation applications beyond the clinical setting such as environmental disinfectants.

Keywords: photodynamic inactivation, photodynamic therapy, photosensitizer, reactive oxygen species, permeability barrier, multidrug efflux systems, biofilms, clinical applications

\section{INTRODUCTION}

\section{FUNGAL INFECTIONS AND COUNTERMEASURES}

Fungi are common causative agents of diseases in both the immune competent as well as the immune compromised patient

\footnotetext{
Abbreviations: ABC, ATP binding cassette; ALA, 5-aminolevulinic acid; APDI, antimicrobial photodynamic inactivation; BCVA, best-corrected visual acuity; BSI, blood stream infections; CDR1, Candida drug resistance 1; CFU, colony forming unit; $\mathrm{CMD}$, choroidal major diameter; $\mathrm{CNV}$, choroidal neovascularization; $\mathrm{EPI}$, efflux pump inhibitor; ETC, electron transport chain; EtNBSe, selenium analog of benzophenothiazinium salt; HOMO, highest occupied molecular orbital; IA, invasive aspergillosis; IC, invasive candidiasis; IL-1, interleukin-1; LUMO, lowest occupied molecular orbital; MAL, methyl 5-aminolevulinic acid; MB, methylene blue; MDR1, multidrug resistance 1; MFS, major facilitator superfamily; MIC, minimal inhibitory concentration; NMB, new methylene blue; PDI,
}

populations. The diseases include cutaneous, subcutaneous, mucosal invasion, and can be found as blood stream infections (BSI) that are life-threatening (Gavalda et al., 2005; Sobel, 2007; Caston-Osorio et al., 2008; Ameen, 2009; Horn et al., 2009; Neofytos et al., 2009; Pappas et al., 2009). Dermatophytosis is probably the most prevalent of all fungal diseases but also the least studied in regard to host-fungus interactions (Vermout et al., 2008).

\footnotetext{
photodynamic inactivation; PDR, pleiotropic drug resistance; PDT, photodynamic therapy; PEI-ce6, polyethyleneimine-chlorin(e6); PMMA, poly-methyl methacrylate; PS, Photosensitizer; RB, rose bengal; RD, respiratory deficiency; RND, resistant nodulation (cell) division; RNS, reactive nitrogen species; ROS, reactive oxygen species; SOR1, singlet oxygen resistance 1; TBO, toluidine blue.
} 
Fungal diseases are endemic in certain parts of the world and include blastomycosis, chromoblastomycosis, coccidioidomycosis, histoplasmosis, paracoccidioidomycosis, penicilliosis, or pandemic including invasive aspergillosis (IA), invasive candidiasis (IC), cryptococcosis, dermatophytosis, fusariosis, and mucormycosis. Very likely, the greatest threat to life results from those pathogens that cause BSI, yet with IA and IC diagnosis is not easy and often these diseases are treated empirically when blood cultures are negative for bacterial pathogens. In the case of IC, there can be numerous risk factors that, for the most part, are nonspecific. Candida spp. are the third leading cause and are associated with the highest mortality of catheter-related infections (Crump and Collignon, 2000). Although prevention of IC using azole prophylaxis can be effective in selected high-risk patient populations, selection for invasive infection by resistant non-albicans Candida species or molds is a potentially devastating consequence. Despite improvements in antifungal therapy, the mortality rate due to Candida BSI has improved little over the last two decades, remaining high at 15-49\% (Gudlaugsson et al., 2003). A BSI episode significantly increases cost of care. In one analysis, the estimated cost of an IC BSI episode was $\$ 34,123$ per Medicare patient and $\$ 44,536$ per private insurance patient (1997, US\$), with an overall economic burden of $\$ 2$ billion dollars annually in the USA (Rentz et al., 1998).

The increased infection of immunocompromised hosts is dramatically illustrated by Cryptococcus neoformans, a pathogen that rose to prominence as the causative agent of cryptococcosis, which is a life-threatening disease that has emerged in parallel with the HIV/AIDS epidemic. Cryptococcosis results from inhalation of fungal cells with subsequent lung infection and pneumonia. In the absence of an effective immune response, the fungus can disseminate to the brain to cause meningoencephalitis, the symptoms of which include headache, fever, visual problems, and an altered mental state (Brizendine and Pappas, 2010). C. neoformans causes an estimated one million cases of meningoencephalitis globally per year in patients with AIDS, leading to approximately 625,000 deaths (Park et al., 2009). The bulk of this disease incidence is in sub-Saharan Africa, where fatal cases of cryptococcosis may exceed deaths from tuberculosis in some areas (Park et al., 2009). The importance of immune suppression in predisposition to infection has been challenged by the recent discovery of specialized interactions between the fungus and its mammalian hosts, and by the emergence of the related species Cryptococcus gattii as a primary pathogen of immunocompetent populations (D'Souza et al., 2011). A set of recently discovered cryptococcal pathogenesis features reveal the fungal adaptation to the mammalian environment (Alanio et al., 2011). These features include not only remarkably sophisticated interactions with phagocytic cells to promote intracellular survival, dissemination to the central nervous system, and escape (Alanio et al., 2011; Kronstad et al., 2011), but also surprising morphological and genomic adaptations such as the formation of polyploid giant cells in the lung (Fuchs et al., 2010).

The state of the art in antifungal drug discovery includes only a few new compounds which offer some hope for eradication of fungal diseases (Ostrosky-Zeichner et al., 2010). Specifically: (1) the echinocandins act against a specific component of fungal pathogens. As such, their safety profile is quite good, unlike triazoles that are notorious for causing drug-drug interactions and toxicity; (2) the formulation of amphotericin B was changed to achieve better absorption as this drug is now available as a lipid formulation encapsulation. This modification has reduced toxicity due to off-target effects on host cells but has an increased cost; (3) enhanced activity has been observed with two of the newer triazoles, posaconazole, and voriconazole; (4) new triazoles are in development (albaconazole and ravuconazole); (5) echinocandins are slow in development and ineffective against $C$. neoformans. While $\beta$-1,3-glucan is present in the cell wall of this pathogen, caspofungin may have reduced activity against the $\beta$-1,3-glucan synthase (Feldmesser et al., 2000); (6) drug resistance to triazoles is a common feature of several species of Candida; an increase in resistance to echinocandins is frequently reported; and, importantly, (7) the impressive number of references to resistance developing to antifungals (Pfaller et al., 2010) makes the development of new antifungal countermeasures a necessity. One promising antifungal modality is the light-based technology of photodynamic therapy (PDT). This review summarizes the progress in antifungal PDT attempting to formulate the principles as well as the concepts for its successful implementation.

\section{THE PLATFORM OF PHOTODYNAMIC THERAPY}

Photodynamic therapy (St. Denis et al., 2011a) was discovered in 1900 by Oskar Raab and Hermann von Tappeiner who found that Paramecium spp. protozoans were killed after staining with acridine orange and subsequent exposure to bright light (Raab, 1900 ). In the 1970s, PDT was initially developed as a therapy for cancer after it was discovered that porphyrins selectively localized in tumors (Mitton and Ackroyd, 2008). Since then, PDT has been clinically used for treatment of various malignancies and is an approved therapy for destruction of choroidal neovascularization $(\mathrm{CNV})$ in age-related macular degeneration. Recently, antimicrobial PDT has been proposed as an alternative approach for localized infections (St. Denis et al., 2011a).

Photodynamic therapy involves the use of a non-toxic lightsensitive dye called a photosensitizer (PS) combined with harmless visible light of the appropriate wavelength to match the absorption spectrum of the PS. After photon absorption the PS reaches an excited state that can undergo reaction with ambient oxygen, resulting in the formation of reactive oxygen species (ROS). PDT is a highly selective modality as (i) the PS can be targeted to the unwanted cells or tissue (Hunt, 2002) and (ii) cell death is spatially limited to regions where light of the appropriate wavelength is applied. Since some PS bind rapidly and selectively to microbial cells, it was suggested that PDT could be used as anti-infective approach; this became a reality in the mid 1990s (Nitzan et al., 1992).

\section{THE PHOTOPHYSICAL PROCESSES OF PDT}

The three principle components of PDT are the PS, visible light, and oxygen. These individually harmless components, when combined, yield potent ROS (Figure 1). Dyes have molecular structures that are typified by conjugated double bonds containing a delocalized system of $\pi$-electrons. In the PS ground (singlet) state, these electrons are spin paired in low energy orbitals. Upon application of light corresponding to the absorption peak of the PS, the 


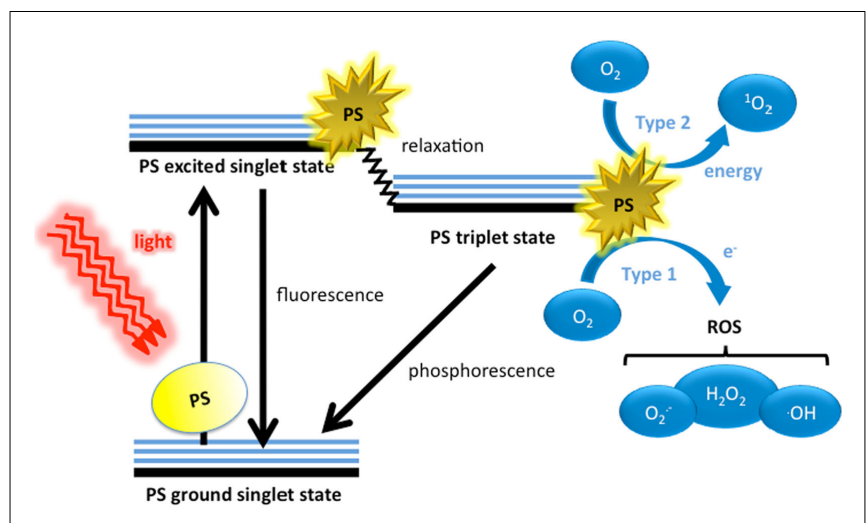

FIGURE 1 | Schematic illustration of photodynamic therapy including the Jablonski diagram. The PS initially absorbs a photon that excites it to the first excited singlet state and this can relax to the more long lived triplet state. This triplet PS can interact with molecular oxygen in two pathways, type I and type II, leading to the formation of reactive oxygen species (ROS) and singlet oxygen respectively.

electron in the highest occupied molecular orbital (HOMO) of the PS is excited to the lowest unoccupied molecular orbital (LUMO), exciting the PS to an unstable, and short lived excited singlet state. In this state, several processes may rapidly occur (Foote, 1991). The most important of these to the PDT process is the reversal of the excited electron's spin, known as intersystem crossing to give the triplet state of the PS. This triplet state is less energetic than the excited singlet state, but has a much longer lifetime (microseconds as opposed to nanoseconds), as the excited electron, now with a spin parallel to its former paired electron, may not immediately revert to a lower energy level according to the Pauli Exclusion Principle. Accordingly, the excited electron in the PS triplet state may change its spin orientation (a relatively slow process) and emit its energy as phosphorescence, or alternatively the triplet PS may interact with molecules abundant in its immediate environment. Because of the selection rules that specify that triplet-triplet interactions are spin-allowed while triplet-singlet interactions are spin-forbidden, the PS triplet can react readily with molecular oxygen that is one of the few molecules that are a triplet in the ground state (Figure 1).

\section{THE PHOTOCHEMICAL GENERATION OF OXIDIZING SPECIES}

The ability of PDT to produce ROS needs the presence of molecular oxygen $\left(\mathrm{O}_{2}\right.$; Foote, 1991; Tanielian et al., 2000). As mentioned above, the ground electronic state of oxygen is a triplet, whereby the two outermost orbitals are unpaired but spin parallel and this triplet can undergo energy transfer upon collision with the excited PS triplet. This Type II process involves "flipping the spin" of the outermost $\mathrm{O}_{2}$ electron and shifting it into the orbital containing the other electron, which in turn leaves one orbital entirely unoccupied (a violation of Hund's rule). Termed singlet oxygen $\left({ }^{1} \mathrm{O}_{2}\right)$, this form of oxygen (not considered a radical as its electrons are spin paired) is extremely short lived and reactive, owing to its electron configuration instability. An alternative photochemical mechanism is termed the Type I when the PS triplet directly transfers an electron, sometimes in concert with proton donation to
$\mathrm{O}_{2}$, yielding superoxide anion $\mathrm{O}_{2}^{\bullet-}$ ) which can then go on to form other ROS including the hydroxyl radical $(\bullet \mathrm{OH})$, and hydrogen peroxide $\left(\mathrm{H}_{2} \mathrm{O}_{2}\right)$.

The ROS formed through the Type 1 process have a range of different reactivities (Ochsner, 1997). ${ }^{\bullet} \mathrm{OH}$, arguably the most reactive of the three ROS formed, is a strong electrophile that is able to chemically attack a very wide range of biomolecules. $\mathrm{H}_{2} \mathrm{O}_{2}$ is less reactive and $\mathrm{O}_{2}^{\bullet-}$ is least reactive. Nonetheless, $\mathrm{O}_{2}^{\bullet-}$ may be converted to $\mathrm{H}_{2} \mathrm{O}_{2}$ and $\mathrm{O}_{2}$ by superoxide dismutase. $\mathrm{H}_{2} \mathrm{O}_{2}$ is only considered truly reactive when it reacts with ferrous iron in what is known as the Fenton reaction.

$\mathrm{H}_{2} \mathrm{O}_{2}+\mathrm{Fe}^{2+} \rightarrow \mathrm{OH}^{-}+\cdot{ }^{\bullet} \mathrm{OH}+\mathrm{Fe}^{3+}$

which results in the homolytic fission of the oxygen-oxygen bond in $\mathrm{H}_{2} \mathrm{O}_{2}$ to yield a hydroxide ion and ${ }^{\bullet} \mathrm{OH}$ via the oxidation of ferrous iron to ferric iron (Valko et al., 2005). $\mathrm{H}_{2} \mathrm{O}_{2}$ is removed through catalase, forming water, and oxygen gas. Although $\bullet \mathrm{OH}$ is not broken down by an enzymatic reaction, it may be quenched by antioxidants, including antioxidant peptides (e.g., glutathione) or by antioxidant vitamins (e.g., ascorbic acid).

Because ${ }^{1} \mathrm{O}_{2}$ is not a radical, it reacts with biological molecules through quite different mechanisms, making the Type II pathway responsible for different macromolecular reaction pathways. ${ }^{1} \mathrm{O}_{2}$ tends to favor reacting with double bonds and sulfur moieties (both of which have high electron densities) and may interact with aromatic components of macromolecules in Diels-Alder cycloadditions (Leach and Houk, 2002; Singleton et al., 2003), ${ }^{1} \mathrm{O}_{2}$ is unable to be broken down by enzymes but can be quenched by antioxidants.

\section{PROPERTIES OF PHOTOSENSITIZERS}

Photosensitizer are usually organic delocalized aromatic molecules consisting of large conjugated systems of double bonds that may be considered as a central chromophore with auxiliary side chains attached (auxochromes) which are responsible for further electron delocalization of the PS, thus altering the absorption spectra of the PS (Wainwright et al., 2006). Due to extensive electron delocalization, PS tend to be deeply colored. This means that the energy required to excite the electrons in the HOMO to the LUMO is low compared to less delocalized molecules and therefore the absorption bands are in the longer wavelength (red) spectral region and are large, reflecting the high probability of excitation. Acridine orange was the first photodynamic agent used (Takahashi et al., 1975). Most of the PS that have been employed for the treatment of cancer and other tissue diseases are based on the tetrapyrrole nucleus, which were initially porphyrins. Due to the unfavorable absorption spectrum of porphyrins (low peaks in the 630-nm region), emphasis then shifted to other tetrapyrroles such as chlorins, bacteriochlorins, and phthalocyanines that have much larger peaks at longer red wavelengths where tissue transmission of light is maximal. While these tetrapyrroles were initially studied as antimicrobial PS, their inability to kill pathogens that belonged to other classes than Gram-positive bacteria led to the proposal of dyes with different molecular frameworks as antimicrobial PS (Sharma et al., 2011). Phenothiazinium salts, such as methylene blue (MB) and new methylene blue (NMB; Figure 2A,B respectively; Harris et al., 2005; Souza et al., 2010) are often used since 
A<smiles>CN(C)c1ccc2nc3ccc(=[N+](C)Cl)cc-3sc2c1</smiles>

C Methylene blue<smiles>CCN(CC)c1ccc2c(c1)[Se]c1cc(=[N+](CC)CC)c3ccccc3c-2n1</smiles>

$\mathbf{E}$

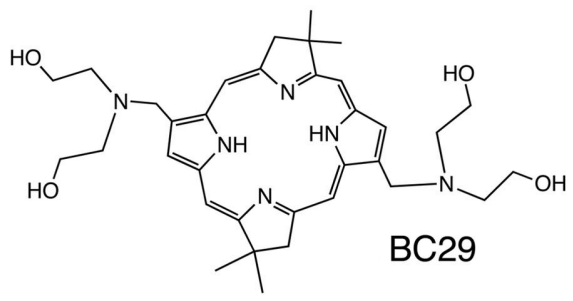

$\mathbf{F}$

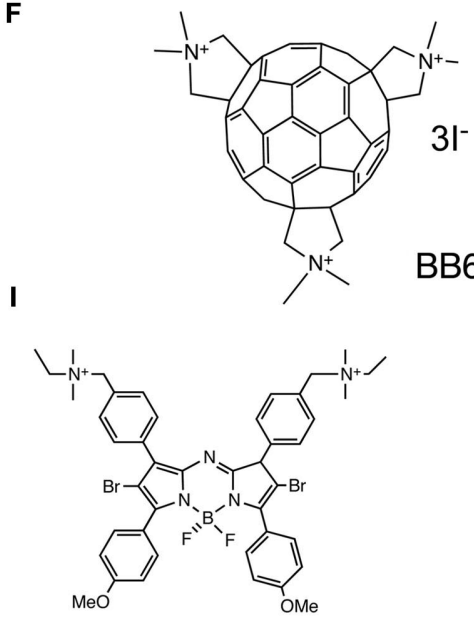

BF2 chelated dipyrromethene

H
B<smiles>CCNc1cc2[se+]c3cc(NCC)c(C)cc3nc2cc1C</smiles>

D New methylene blue<smiles>CN(C)c1ccc(C(=C2C=CC(=[N+](C)C)C=C2)c2ccccc2)cc1</smiles>

G Malachite green oxalate

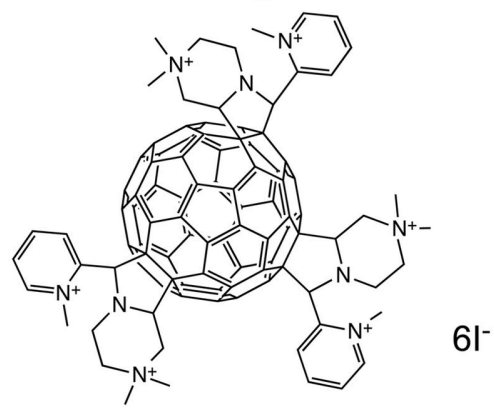

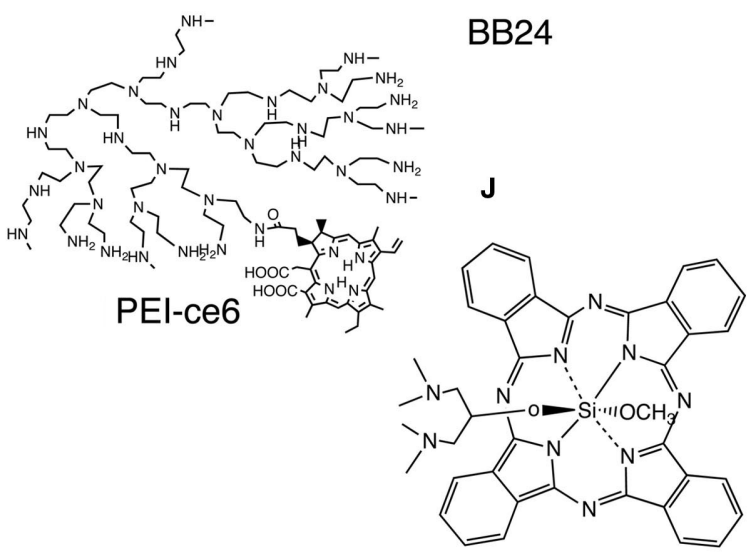

BAM SiP

FIGURE 2 | Representative chemical structures of PS that have been reported to be especially active in the photoinactivation of fungal cells. (A) Methylene blue, MB, (B), new methylene blue, NMB (Dai et al., 2011a); (C), selenium Nile blue analog, EtNBSe (Foley et al., 2006); (D), malachite green oxalate, (E), bis-amino-substituted bacteriochlorin, BC29 (Huang et al., 2010a); (F), tris-N-methyl-pyrrolidinium fullerene, BB6 (Tegos et al., 2005); (G), hexakis-cationic fullerene BB24 (Huang et al., 2010b);
(H). Conjugate between polyethylenimine and chlorine (e6), PEl-ce6 (Tegos et al., 2006); (I), BF2 Chelate of N-(4-(4-Bromo-2-

(4-bromo-3-(4-((diethyl(methyl)-ammonio)methyl)phenyl)-5-(4-

methoxyphenyl)-1 $\mathrm{H}$-pyrrol-2-ylimino)-5-(4-methoxyphenyl)-2H-pyrrol-3yl)benzyl)- $N$-ethyl- $N$-methylethanaminium iodide (Frimannsson et al., 2010); (J), 1,3-bis(dimethylamino)-2-propoxy-methoxy silicon phthalocyanine, BAM-SiPc (So et al., 2010). they were the first antimicrobial PS to be tested and are clinically approved for human use. Although there has been a wide range of antimicrobial PS reported, it is becoming clear that the optimal structures for inactivating bacterial cells and the optimum structure for fungal cells may in fact be subtly different from those used for cancer. Some structures such as protease-stable polycationic (PS) conjugates between polyethyleneimine and chlorin(e6), PEI-ce6, (Figure 2H; Tegos et al., 2006), tris-cationic substituted fullerenes (BB6; Figure 2F), hexakis-cationic fullerenes (BB24; Figure 2G), the cationic porphyrin TriP[4], (Lambrechts et al., 2005), and the selenium analog of benzophenothiazinium salt (EtNBSe; Figure 2C) may be equally potent to mediate photo 
killing of bacteria and fungi. However other structures, including PS that are usually considered to be specific for killing cancer cells, have also been reported to be effective in killing fungal cells (mainly C. albicans). This applies to PS such as Photofrin (Bliss et al., 2004), $\mathrm{Al}$ (III)-tetrasulfonated phthalocyanine (Bertoloni et al., 1992; Lazarova, 1993; Bliss et al., 2004), and PC4 silicon phthalocyanine (Lam et al., 2011). Moreover some PS that are highly effective in killing Gram-positive and Gram-negative bacteria are not very effective in killing fungal cells. It appears that having a large number of cationic charges is important for efficient photodynamic inactivation (PDI) of Gram-negative bacteria and to a lesser extent Gram-positive bacteria, but this structural feature does not provide good binding or penetration into fungal cells. Rather, more lipophilic structures with a lower amount of cationic charge seem to be better for fungal cells. An example of this latter class is the bacteriochlorin (BC29; Figure 2E) that was effective at killing Candida cells, while analogs with more cationic charges were better at killing bacteria (Huang et al., 2010a). The list of PS targeting exclusively C. albicans is expanding and include malachite green (Figure 2D; Souza et al., 2010) an unsymmetrical bis-amino phthalocyanine bis-amino silicon (IV) phthalocyanine (BAM-SiPc; Figure 2J; So et al., 2010). A brominated boron difluoride $\left(\mathrm{BF}_{2}\right)$ chelated tetraarylazadipyrromethene photosensitizer (Figure 2I; Frimannsson et al., 2010) reduced in combination with light the viability of yeast cells [5.7 log (10)]. Photodithazine, a glucosamine salt of chlorin e6, enhanced the inactivation of C. guilliermondii cells by visible light (Strakhovskaia et al., 2002).

As microorganisms produce and accumulate porphyrins, the appealing hypothesis of endogenous photosensitization is also an alternative pathway of photoinactivation (Oriel and Nitzan, 2010). In this approach a small non-dye aminoacid (5-aminolevulinic acid, ALA) is administered as it has been shown that exogenously supplied ALA enters into the microbial heme biosynthetic pathway and results in an accumulation of excess protoporphyrin IX than can act as a moderately effective PS. In an alternative approach, extracts from Alternanthera maritima (seaside joyweed) with an absorption range at $650-700 \mathrm{~nm}$ can effectively photoinactivate Candida dubliniensis. The chemical compositions of the extracts were determined by chromatographic and spectroscopic techniques. The results suggest inhibition of the growth of $C$. dubliniensis after being irradiated with a $685-\mathrm{nm}$ diode laser irradiation alone or crude extracts at $25 \mathrm{mg} / \mathrm{ml}$ did not significantly reduce the number of colony forming units (CFU) per milliliter. Steroids, triterpenes, and flavonoids were identified in the analyzed extracts (Gasparetto et al., 2010).

\section{BYPASSING THE PERMEABILITY BARRIER}

Bypassing the permeability barrier is a common and challenging theme in antimicrobial drug discovery. Yeasts and fungal pathogens are variable in their cell envelopes, possessing outer wall mixtures of glucans, mannan, and chitin polymers. This feature makes them inherently more permeable to external substances than Gram-negative bacteria. In one of the first reports for antifungal PDI, Toluidine blue (TBO) was tested against Kluyveromyces marxianus (Paardekooper et al., 1992). Apart from ability of the
PS to eradicate a microbial population the influence of PDI on the barrier properties of the plasma membrane was studied. TBO mediated PDI-induced a permeability change proceeding in an "all-or-none" fashion which was reflected in potassium ions and E260-absorbing material efflux, reduction of the cell volume, and vacuole integrity. Finally, it was observed that the loss of cell viability was not induced by the all-or-none loss of barrier properties (Paardekooper et al., 1992). A recent study claims that MB-mediated PDI increases membrane permeability in C. albicans (Giroldo et al., 2009).

The combination of the anionic PS rose bengal (RB) with glutathione was effective in killing C. albicans. Although the key hypothesis was enhancement of PDI involving stimulation of the singlet oxygen generation, the effect of glutathione on the permeability barrier of eukaryotic cells is well established. Alternatively, compounds that create pores within the fungal membrane have shown increased influx of PS compounds that are otherwise unable to enter the cytosol. Phytoalexins of the saponin family are able to bind to the fungal sterol ergosterol, creating pores in the membrane resulting in cellular leakage (Simons et al., 2006). Pretreatment of C. albicans cells with a sub inhibitory concentration of a saponin significantly increased the uptake of the PS molecules RB and chlorin (e6), and was able to decrease the survival fraction after exposure with the correct wavelength of a low-intensity light (Coleman et al., 2010). The degree of C. albicans killing was 2-5 logs greater in the presence of the saponin when compared to the PS molecules alone. Pretreatment of the saponin did not result in any significant increase in C. albicans killing when PEI-ce6 was used as the PS, presumably because of the high permeability of the conjugated PS molecule. Confocal microscopy revealed that ce6 resulted in minimal cellular uptake in C. albicans, however co-incubation of the PS and the saponin for $1 \mathrm{~h}$ resulted in a visible increase of PS within the C. albicans cytosol (Figure 3). Collectively, this study suggests in addition to saponins, other compounds with fungal pore-forming properties could be used in conjunction with a PS molecule, and compounds with antifungal efficacy derived by pore-forming ability such as the polyenes (amphotericin B and nystatin) may be a potent treatment strategy for fungal infections.

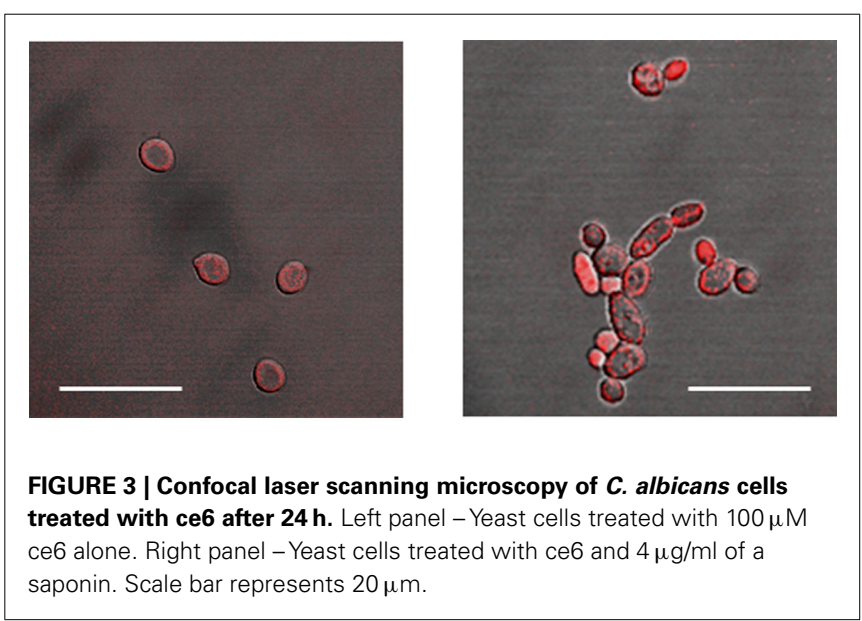




\section{PDI FOR AZOLE AND ANTIFUNGAL RESISTANT PHENOTYPES}

There is documented evidence that PDI is equipotent against both antimicrobial-resistant and susceptible microorganisms (St. Denis et al., 2011a). This may be observed in azole-resistant and susceptible Candida spp. PDI employing Photogem ${ }^{\circledR}$ as a PS with a light emitting diode had a significant effect against fluconazole-resistant C. albicans and Candida glabrata (Dovigo et al., 2011a). A set of clinical isolates from adult HIV patients, including strains highly resistant and sensitive to fluconazole and amphotericin $\mathrm{B}$, were subjected to Photofrin ${ }^{\circledR}$ mediated PDI using a $630 \mathrm{~nm}$ laser and the appropriate time to deliver $45-135 \mathrm{~J} / \mathrm{cm}^{2}$. There was not substantial difference in the survival fractions between resistant and sensitive isolates (Mang et al., 2010).

However, early stationary phase yeast forms of C. albicans and C. glabrata were not adversely affected by treatment. Respiratorydeficient (RD) strains of C. albicans and C. glabrata display a pleiotropic resistance pattern, including resistance to azole antifungals, the salivary antimicrobial peptides histatins, and certain types of toxic stresses. The cationic porphyrin PS meso-tetra $(N-$ methyl-4-pyridyl) porphine tetra tosylate (TMP-1363) is effective in PDT against yeast forms of C. albicans and C. glabrata. In contrast to this pattern, RD mutants of both C. albicans and C. glabrata were significantly more sensitive to PDI compared to parental strains. These data suggest that intact mitochondrial function may provide a basal level of antioxidant defense against PDI-induced phototoxicity in Candida spp., and reveals pathways of resistance to oxidative stress that can potentially be targeted to increase the antifungal efficacy of PDT (Chabrier-Roselló et al., 2008). Curcumin, a naturally occurring pigment with a maximum absorption peak in the short wavelength range between 408 and $430 \mathrm{~nm}$ has been recently used for successful PDI in clinical isolates of Candida spp. (Dovigo et al., 2011b).

\section{INACTIVATION OF CRYPTOCOCCUS AND OTHER FUNGAL PATHOGENS}

Recent studies have revealed a substantial PDT effect both in Cryptococcus spp. as well as a variety of fungal pathogens. These include both mechanistic and conceptual PDI studies. Stress sensors detect ROS and the cell wall elicits a response noted by the activation of Slt2 for Saccharomyces cerevisiae or Mpk1 for C. neoformans (Vilella et al., 2005; Gerik et al., 2008). In C. neoformans PKC1 is essential for defense against oxidative stress, both in the form of hydrogen peroxide and the thiol oxidizing agent, diamide (Gerik et al., 2008).

For the C. neoformans cell wall defective strain KN99a rom2, the PS PEI-ce6 exhibited an increased association with KN99 $\alpha$ rom2, which was observed to penetrate the cell (Fuchs et al., 2007b; Figure 4). Rom2 is a guanyl nucleotide exchange factor in the cell wall integrity pathway, relaying the activation of the sensors by extracellular stressor to the signaling cascade that initiates the phosphorylation events of the mitogen activated protein kinase (MAPK) cascade (Ozaki et al., 1996; Philip and Levin, 2001). The association and ability of the PS to penetrate and collect within the cell was likely due to defects in the cell that prevent the PS from being excluded. The rom 2 mutant is characterized by a $35 \%$ reduction in the amount of $\beta$-glucan and physical disparities in the cell wall observable through transmission electron microscopy

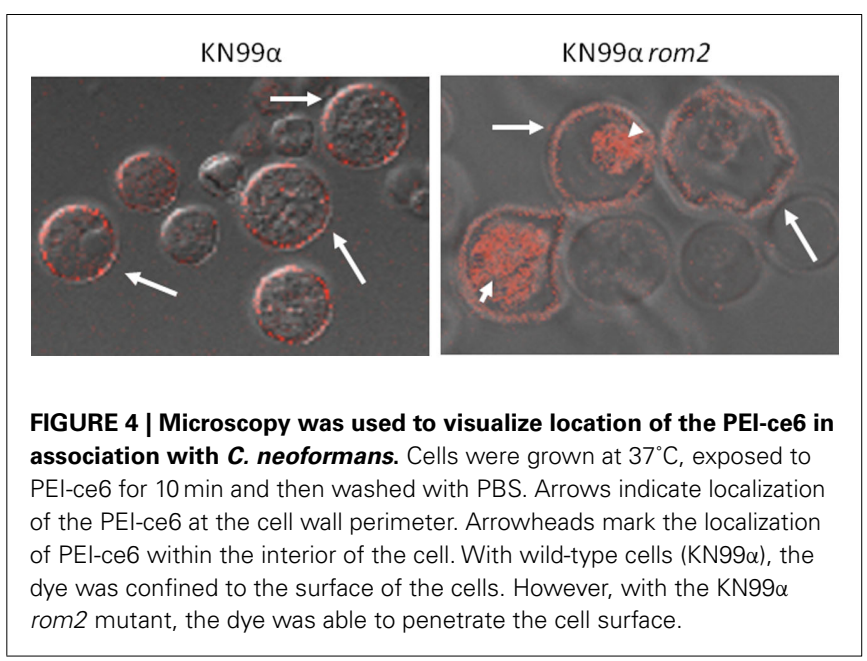

(TEM). Cell wall defects are enhanced at the high temperature growth condition $37^{\circ} \mathrm{C}$, a stress condition for the cell (Fuchs et al., 2007a). The lack of a stable cell wall structure is likely associated with the actin and microtubule defects, cytoskeletal components needed to transport structural components to the cell wall and maintain a rigid configuration and uniform shape. The result of the culmination of defects was an increase in cell death upon application of the activated PS.

Interestingly, cell death was enhanced with the addition of the antifungal caspofungin. While caspofungin is effective against other fungal pathogens, including C. albicans, it fails to exhibit fungicidal effects against $C$. neoformans, for reasons that have not yet been fully elucidated (Abruzzo et al., 1997; Espinel-Ingroff, 1998). As a member of the echinocandin class of drugs, caspofungin targets the glucan synthase Fks1p. In this case, the inclusion of caspofungin enhanced the killing of the activated PS. Even though it does not kill C. neoformans, caspofungin is known to affect the $\beta$-glucan linkages (Feldmesser et al., 2000). It is suspected that the combination of the two cell wall targeted compounds dually damaged the cell enough to lead to cell death or that caspofungin weakened the cell to allow for greater penetration of the PS that led to cell death. The results suggest that external sources of ROS can be applied as a means to inhibit fungi. Potentially, it could enhance the fungicidal activity of compounds that target or weaken the cell wall.

A second study tested the effectiveness of TBO employing $C$. gattii strains with distinct susceptibility profile to amphotericin $\mathrm{B}$ and azoles. The concept of equipotent PDI between susceptible and resistant isolates was re-confirmed. A more detailed mechanistic study was attempted including determination of ROS and reactive nitrogen species (RNS, e.g., peroxynitrite) production and the catalase and peroxidase activities were measured (Soares et al., 2011).

A variety of reports tested the use of different PS and explored optimal conditions and the morphological changes observed upon PDI of the dermatophyte Trichophyton rubrum (Kamp et al., 2005; Smijs et al., 2007, 2008; Smijs and Pavel, 2011). The list of PDIinactivated fungal species has been increasing exponentially. Trichophyton mentagrophytes, Trichophyton tonsurans, Microsporum 
cookei, Microsporum gypseum, Microsporum canis, Epidermophyton floccosum, Nannizia cajetani, Metarhizium anisopliae, Aspergillus nidulans, A. fumigatus, and Fusarium sp., have been tested with a variety of different PS, offering a new avenue for antifungal therapies (Friedberg et al., 2001; Calzavara-Pinton et al., 2005; Gonzales et al., 2010).

\section{FUNGAL EFFLUX SYSTEMS AS A PDI TARGET}

There are two main types of fungal drug efflux systems (Cannon et al., 2009). (1) The major facilitator superfamily (MFS) transporters use the electrochemical gradient across the plasma membrane to expel drugs from cells, and (2) ATP binding cassette $(\mathrm{ABC})$ transporters, in contrast, use ATP binding and hydrolysis to efflux drugs. Although fungal cells contain many genes for both types of systems, clinical azole resistance is most often associated with overexpression of $\mathrm{ABC}$ transporters (Holmes et al., 2008; Cannon et al., 2009). There are several classes of fungal $\mathrm{ABC}$ transporters, and the pleiotropic drug resistance (PDR) family is often responsible for fungal drug resistance (Lamping et al., 2010). Clinically important PDR transporters include C. albicans Cdr1p (CaCdr1p) and CaCdr2p, which are homologs of the Saccharomyces cerevisiae Pdr5p (ScPdr5p) and mammalian G-type ABC transporters (Holmes et al., 2006, 2008; Cannon et al., 2009). Fungal PDR efflux systems have relatively promiscuous substrate specificities that are presumably defined by their transmembrane domains. These specificities often partially overlap among family members in a particular organism and thus provide broadspectrum protection against xenobiotic threats, including those posed by the widely used and well-tolerated azole and triazole drugs.

The role of multidrug efflux in antimicrobial PDT resistance has only recently come under scientific investigation. Phenothiazinium dyes $\mathrm{MB}$ and $\mathrm{TBO}$ are amphipathic cations and physicochemically similar to the antibacterial alkaloid berberine, a wellcharacterized substrate of MFS efflux systems in Gram-positive bacteria (Tegos et al., 2002). This similarity raised the possibility that phenothiazinium PS could also be substrates of microbial efflux systems. Recent experimental evidence indicated that phenothiaziniums were NorA (MFS) substrates in S. aureus and possibly MexAB resistance nodulation (cell) division (RND) substrates in P. aeruginosa (Tegos and Hamblin, 2006). The observation that $\mathrm{ABC}$ transporters and not MFS affect MB-mediated antimicrobial PDI (APDI) in the pathogenic yeast C. albicans is perplexing (Tegos and Hamblin, 2006; Prates et al., 2011). Prates et al. tested this hypothesis by comparing MB-PDI for two pairs of isogenic C. albicans strains (i) YEM 12 and YEM 13 mutant overexpressing MDR1 MFS; and (ii) YEM 14 and YEM 15 mutant overexpressing CDR1/CDR2 (Figure 5). Since efflux systems affect APDI of MB in C. albicans, a logical strategy was to explore whether efflux pump inhibitors (EPIs) could potentiate APDI with MB. They used two well-documented EPIs, one for each corresponding efflux system, $\mathrm{INF}_{271}$ (targeting MFS) and verapamil (+; targeting ABCs both in yeast and mammalian systems) and the reference $C$. albicans strain DAY185. Pre exposure to $\mathrm{INF}_{271}$ followed by MB-mediated PDI, resulted in a paradoxical protection rather than enhancement of phototoxicity. On the other hand, pre exposure of C. albicans cells to verapamil $(+)$ and subsequent MB-mediated APDI led to an increase of phototoxicity when compared with the PDI efficacy of $\mathrm{MB}$ in the absence of EPIs. In addition, pre exposure of the CDR1/CDR2 overexpressing mutant YEM 15 in verapamil (+) and subsequent APDI revealed 2 logs of cell reduction in the presence of the EPI, in comparison with virtually no effect in the absence of the $\mathrm{ABC}$ pump blocker. The authors demonstrated that $\mathrm{ABC}$ pumps are directly implicated in $\mathrm{MB}$ efflux from the cell cytoplasm. Both the influx and the efflux of MB may be regulated by MFS systems and blocking this gate before incubation with $\mathrm{MB}$ can decrease the uptake and APDI effects. An ABC inhibitor could be usefully combined with MB-APDT for treating C. albicans infections.

This interaction seems to be less obvious for different PS chemotypes. The participation of efflux systems in porphyrin mediated PDI has been implied in mammalian ABC transporter systems (Morgan et al., 2010).

\section{BIOFILM ERADICATION}

Microorganisms in nature thrive through adherence to both living and inanimate surfaces via biofilm formation (Pflumm, 2011). The dense and protected environment of the biofilm, as well as the significantly different phenotypic properties of biofilm cells from free-floating cells of the same species, have been implicated in giving rise to as much as 1000 -fold resistance to antimicrobials (Lewis, 2001). Biofilm formation is a critical event in the development of candidosis, including denture stomatitis (chronic atrophic candidosis), which can affect up to $65 \%$ of edentulous individuals (Chandra et al., 2001). Despite the use of antifungal drugs to treat denture stomatitis, infection can often become re-established. By using a [poly(methyl methacrylate), PMMA] biofilm model, it was demonstrated that $C$. albicans biofilms are potentially highly resistant to the currently used antifungal agents. Drug resistance was also shown to develop with time and correlated with biofilm maturation (Chandra et al., 2001). There is an expanding body of literature regarding PDT-based biofilm eradication strategies, with emphasis on the use of different PS for biofilm related phenotypes and microbial species (Biel, 2010). The eradication of microbial biofilms remains a key challenge in the antifungal discovery agenda and new efforts are required to address a number of clinical conditions. The list includes urinary tract infections, catheter infections, middle-ear infections, formation of dental plaque (Fontana et al., 2009), periodontitis, (Raghavendra et al., 2009) gingivitis, endodontics, (Soukos et al., 2006) osteomyelitis (Bisland et al., 2006), infected contact lenses, endocarditis, and infections of permanent indwelling devices such as joint prostheses heart valves and implants (Schuckert et al., 2006).

There is a wealth of literature describing PDT-based antibiofilm strategies that focuses mostly on the use of different PS against a variety of microbial species (Biel, 2010). In contrast there are only a limited number of studies exploring the effects of PDT on phenotypic biofilm elements (e.g., adhesions; Soares et al., 2008). Moreover, there is no consensus as to which is the most reliable model for evaluating PDT efficacy against biofilms. The majority of published reports use methodologies where biofilms are grown in/on plastic or silicon microtiter plates and surfaces. These bioassays have been repeatedly criticized for 


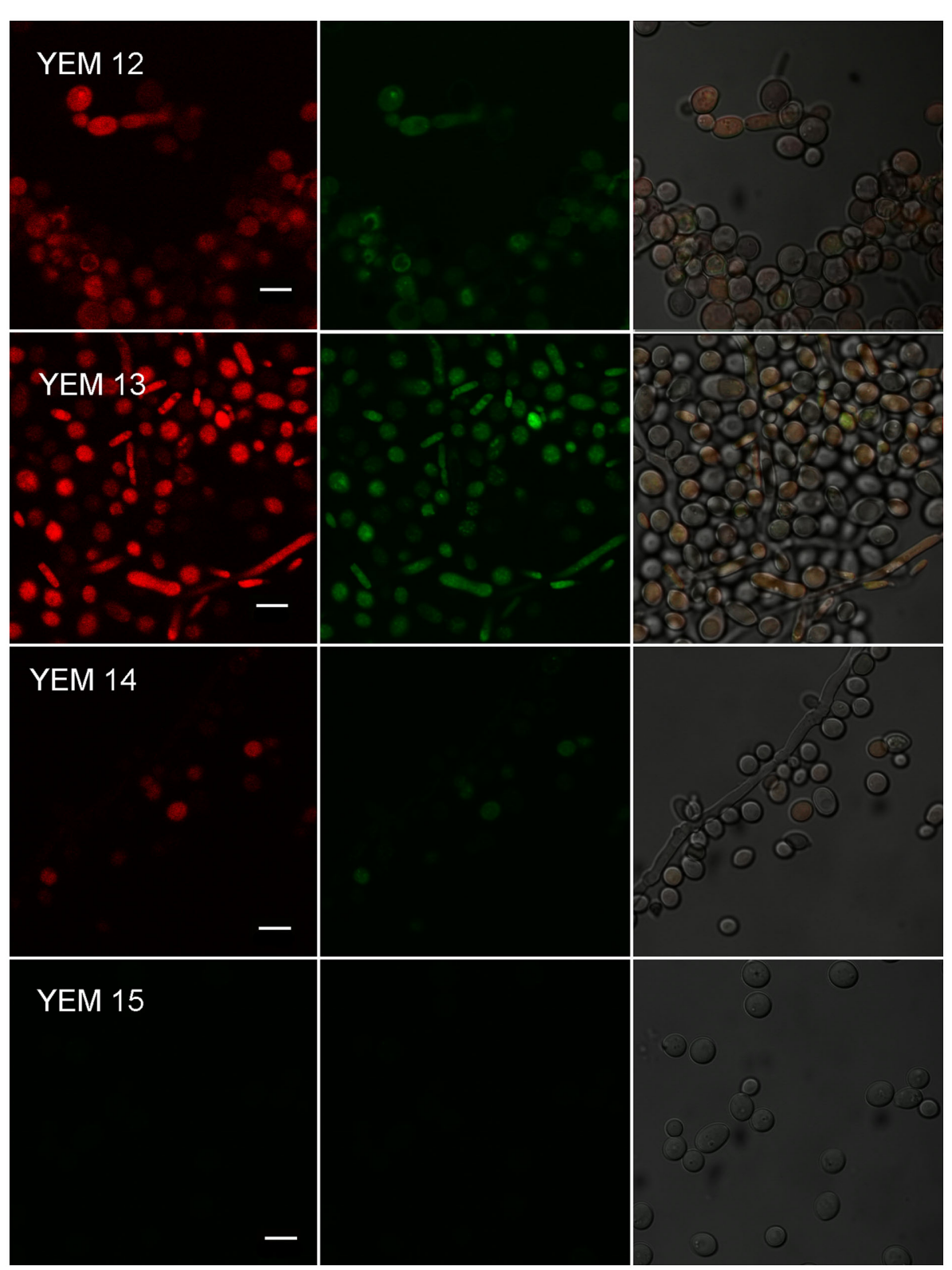

FIGURE 5 | Effect of efflux pumps on photodynamic inactivation of $\boldsymbol{C}$. albicans. Confocal microscopy image of YEM strains. Cells were incubated with $10 \mu \mathrm{M} \mathrm{R} 123$ and $100 \mu \mathrm{M} \mathrm{MB}$ and excited at
$488 \mathrm{~nm}$. We present three pictures of the same field. Red corresponds to the fluorescence of $\mathrm{MB}$ and green corresponds to the fluorescence of R123. lack of robustness and occasionally yield inconsistent results. In this context it has been demonstrated that C. alibcans biofilms are sensitive to Photofrin ${ }^{\circledR}$ PDT (Chabrier-Rosello et al., 2005), C. albicans and C. dubliniensis were susceptible to erythrosinemediated PDT, but the biofilms of both Candida spp. were more resistant than their planktonic counterparts (Costa et al., 2012). The combination of erythrosine- and RB-mediated PDT have some effect in biofilms but also was effective in reducing and destroying of C. albicans blastoconidia and hyphae (Costa et al., 2012). MB-PDT combined with InGaAlP laser (660 nm) exhibited a modest reduction in biofilm $C$. albicans species (Pereira et al.,
2011). In a much more challenging scenario, the combination of gasiform ozone and MB-mediated PDI were unable to reduce the viable counts on a multispecies mature oral biofilm assembled by Actinomyces naeslundii, Veillonella dispar, Fusobacterium nucleatum, Streptococcus sobrinus, S. oralis, and C. albicans (Müller et al., 2007).

The bulk of cells in biofilms are actually highly susceptible to killing by antimicrobials and it is indeed only a small fraction of cells known as persisters that remain alive following antimicrobial treatments (Lewis, 2010). Persisters represent a subpopulation of cells that spontaneously go into a dormant, non-dividing state. 
When a population is treated with a fungicidal antibiotic, regular cells die but the persisters survive. This persister phenotype hypothesis has been proven for $C$. albicans biofilms using amphotericin B and chlorhexidine (Lafleur et al., 2006) as well as in patients with long-term oral carriage harbor high-persister mutants (Lafleur et al., 2010). This concept may explain partially the mechanism of action in the success of miconazole to augment PDI-mediated by the porphyrin TMP-1363 and MB in C. albicans (Snell et al., 2011). In this study, a list of antifungals were tested, miconazole and ketoconazole both stimulated ROS production in C. albicans, but only miconazole enhanced the killing of C. albicans and induced prolonged fungistasis in organisms that survived PDI. Although the data suggested that potentiation of antifungal PDI by miconazole is likely to be multi-factorial (Snell et al., 2011) and the models tested were not related with the biofilm phenotypes.

\section{FROM THE ANTIFUNGAL PDI MECHANISM TO THE OUESTION OF RESISTANCE DEVELOPMENT}

The mechanism of photodynamic action have been described as multi-factorial and non-specific (Bertoloni et al., 1989; Gonzales and Maisch, 2012). It involves the damage of fungal cell wall and membrane by ROS. Subsequently, the intra cellular oxidizing species generated by light excitation induce photodamage to multiple cellular targets. The event list includes inactivation of enzymes and other proteins, peroxidation of lipids, leading to the lyses of cell membranes, lysosomes, and mitochondria and finally causing cell death (Gonzales and Maisch, 2012). A recent study employing the PS Pc 4 in planktonic C. albicans cells highlighted the aforementioned proposed sequence of events. Furthermore, changes in nuclear morphology characteristic of apoptosis, which were substantiated by increased externalization of phosphatidylserine and DNA fragmentation following Pc 4-PDI suggesting that apoptotic phenomena were related with fungal cell death (Lam et al., 2011).

Since disruption of electron transport chain (ETC) function increases intracellular levels of ROS in yeast, interference with ETC assembly, or function will enhance antifungal PDT. The metabolic inhibitor antimycin A and defined genetic mutants were used to identify ETC components that contribute to the sensitivity to TMP-1363-PDT in C. albicans, C. glabrata, and S. cerevisiae (Chabrier-Roselló et al., 2010).

The studies and reports discussing the potential of microbes to develop resistance to PDT are scattered, quite controversial, and with a few exceptions they involve bacterial species. The non-selective nature of APDI appears as a competitive advantage in the activation of a specific microbial resistance pathway. In a conventional biological study of routine stress followed by re growth, 5,10,15-tris(1-methylpyridinium-4-yl)-20(pentafluorophenyl)-porphyrin triiodide (Tri-Py(+)-Me-PF) was employed as PS against Vibrio fischeri and E. coli. After ten cycles of partial inactivation followed by re growth, neither of the bacteria developed resistance to the photodynamic process (Tavares et al., 2010). In a similar study, Giuliani et al. (2010) investigated the potential of phthalocyanine RLP068/Cl mediated PDI to induce resistance to the Gram-positive $S$. aureus, the Gramnegative $P$. aeruginosa, and $C$. albicans, using both sensitive and resistant strains. Its ability, following activation by light, to induce resistance in these three major human pathogens after 20 daily passages was studied. Simultaneously for the same strains, the ability of daily sequential subcultures in sub inhibitory concentrations of RLP068/Cl to develop resistant mutants without illumination was evaluated. It was demonstrated that 20 consecutive APDT treatments with RLP068/Cl did not result in any resistant mutants and that, in dark conditions, only $S$. aureus strains had increased minimally inhibitory concentrations (MICs) of RLP068/Cl. However, even in this case, the susceptibility of the mutated bacteria to APDT was not affected by their MIC increase. Ehrenshaft et al. (1998) showed that the SOR1 (singlet oxygen resistance 1) gene present in Cercospora fungi plays a role in the resistance to PS generating singlet oxygen. Studies with SOR1 deficient mutants resulted in cercosporin and PS sensitivity. However, the function of the protein encoded by this gene and the mechanisms involved in Cercospora toxin auto-resistance remain unclear. PDI with RB in the yeast $S$. cerevisiae, demonstrated a role of Yap1p and Skn7p in the defense against singlet oxygen (Brombacher et al., 2006).

Superoxide dismutase is upregulated following protoporphyrinmediated PDI in S. aureus and RB-mediated PDI in S. mutans induces the bacterial heat shock protein GroEL - responsible for refolding denatured proteins to native conformations and stabilizing lipid membranes during stress (Nakonieczna et al., 2010). These observations are in accordance with those of St. Denis et al. (2011b) who demonstrated that sub-lethal PDI stress increased the expression of the two major bacterial heat shock proteins GroEL and Dnak and that exposing E. coli and E. faecalis to heat pretreatment prior to PDI (a positive regulator of GroEL) conferred stress tolerance, increasing E. coli cell viability by $2 \operatorname{logs}$ and $E$. faecalis cell viability by 4 logs.

\section{ANTIMICROBIAL PDT: FROM BENCH TOP TO BED SIDE}

With the results from in vitro studies being promising in a wide array of fungal species, a number of clinical applications for antimicrobial PDT have been tested and performed in vivo. PDT has been proposed for many dental applications due to the accessibility of the oral cavity. Nevertheless, the complexity of oral microflora makes this microenvironment quite challenging for the deployment of novel antimicrobials. An in vivo study using an immunodeficient murine model with oral azole-resistant candidiasis and topical treatment employing $500 \mathrm{mg} / \mathrm{ml} \mathrm{MB}$ combined with red light totally inactivated $C$. albicans in the oral cavity and even prevented the emergence of resistance (Teichert et al., 2002). A second study employed immunosuppressed Swiss mice orally swabbed with C. albicans. Four days after oral inoculation, PDT was performed on the dorsum of the tongue after topical administration of Photogem ${ }^{\circledR}$ and followed by illumination with LED light at 455 or $630 \mathrm{~nm}$. Determination of CFU, histological, and inflammatory response evaluation of the surgically removed tongues after euthanasia (Mima et al., 2010) revealed effectiveness of the approach.

The very nature of PDT makes it ideal for the treatment of skin, wound, and burn infections, all of which are easily accessible for topical application of PS and light. Dai et al. (2011b) reported PDT using phenothiaziniums for prophylaxis and treatment of cutaneous C. albicans infections in mice. A mouse model 
of skin abrasion infected with C. albicans was developed by inoculating wounds with a luciferase-expressing strain and real-time monitoring of the extent of infection non-invasively through bioluminescence imaging. In vitro PDI studies showed that (NMB; Figure 2B) was superior to $\mathrm{TBO}$ and $\mathrm{MB}$. PDT in vivo initiated either at $30 \mathrm{~min}$ or at $24 \mathrm{~h}$ post infection significantly reduced C. albicans burden in the infected mouse skin abrasion wounds (Figure 6; Dai et al., 2011a).

C. albicans ear pinna infection using a mouse model was treated with $0.3 \mathrm{mg} / \mathrm{ml}$ porphyrin TMP-1363 applied topically in combination with $90 \mathrm{~J} / \mathrm{cm}^{2}$ green light. Additionally, the phototoxicity of both TMP-1363 and MB against C. albicans was compared in vitro. TMP-1363 upon irradiation at a fixed fluence of $2.4 \mathrm{~J} / \mathrm{cm}^{2}$ caused more than three logs of $C$. albicans inactivation than $\mathrm{MB}$ at $10 \mathrm{mM}$ incubation concentration for both PS. However, TMP1363 was inefficiently photo excited, since its peak absorption did not coincide with the irradiation lamp source, underestimating the PDI efficacy of TMP-1363. On the other hand, MB absorption peak was compatible with the emission of the lamp source. Consequently the number of photons absorbed by TMP1363 was approximately 10 -fold lower than that absorbed by the equivalent concentration of MB (Mitra et al., 2011) It was concluded that TMP-1363 displayed a more effective microbial killing than MB due to differences in cellular uptake and/or intracellular localization.
Photodynamic therapy also has promising potential in the treatment of superficial fungal skin infections caused by dermatophytes. T. rubrum is responsible for tinea pedis (athelete's foot), fungal folliculitis, onychomycosis, and dermatophytosis (tinea or ringworm). Employing an ex vivo infection model of human stratum corneum of T. rubrum, Smijs et al. (2009) incubated samples with the PS 5,10,15-tris(4-methylpyridinium)-20phenyl- $(21 \mathrm{H}, 23 \mathrm{H})$-porphine trichloride (Sylsens B) and deuteroporphyrin monomethylester. Upon light application, both PS were shown to be active antifungals. Moreover, 5-aminolevulinic acid (5-ALA) and red light has an effect in the treatment of onychomycosis (Donnelly et al., 2005; Kumar and Kimball, 2009). Treatment of refractory fingernail onychomycosis caused by nondermatophyte molds with methylaminolevulinate PDT (Gilaberte et al., 2011).

Chromoblastomycosis is an infection that involves skin and subcutaneous tissues caused by the traumatic inoculation of dematiaceous fungi species, being that the most prevalent are Fonsecaea pedrosoi and Cladophialophora carrionii. A clinical PDT study employing MB as the PS and a LED device as light source for the treatment of chromoblastomycosis showed promising results (Lyon et al., 2011). PDT for distal and lateral subungual toenail onychomycosis caused by $T$. rubrum have been evaluated in single-center open trial (Sotiriou et al., 2010).
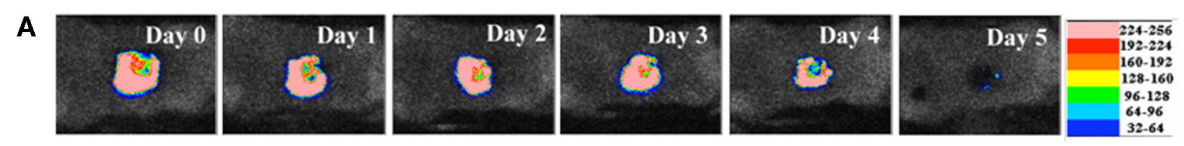

B

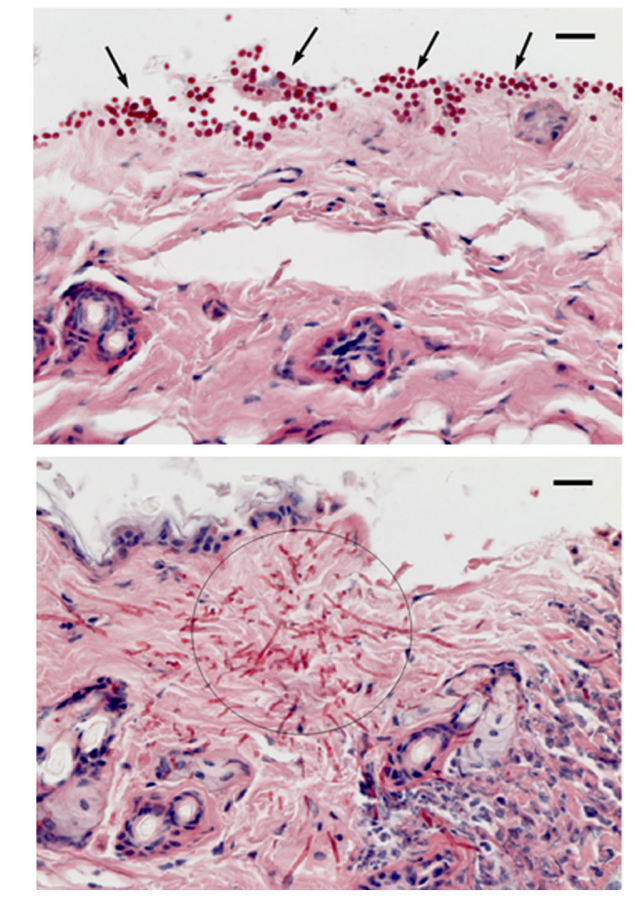

FIGURE 6 | (A) Successive bioluminescence images of a representative mouse skin abrasion infected with $10^{7}$ CFU C. albicans. (B,C) Representative periodic acid-Schiff-stained skin biopsy specimen taken from a mouse skin abrasion infected with $10^{7} \mathrm{CFU}$ C. albicans, showing the presence of yeasts [(B), arrows], hyphal filaments [(C), circle], and inflammatory infiltrate (C). Biopsy was taken on day 1 postinfection. Bar, $20 \mu \mathrm{m}$. 
An evidence-based review of published literature (MEDLINE, EMBASE, and Cochrane Library) was searched until March 2010 and evaluated the efficacy and safety of PDT for superficial mycoses. No randomized clinical trials were found. Seven reports described the antifungal effect of PDT against 63 superficial mycoses patients. Eight of $10(80 \%)$ tinea cruris patients and 6 of $10(60 \%)$ tinea pedis were led to mycological cure after one to three treatments. Four $(40 \%)$ tinea cruris patients and $3(30 \%)$ tinea pedis had a persist healing at the 8-week follow-up. Six of the $9(66.7 \%)$ foot-interdigital mycoses patients recovered clinically and microbiologically after one or four treatments. Only two patients $(22.2 \%)$ had a persist healing at the 8-week followup. Eleven of $30(36.6 \%)$ onychomycosis patients were cured for 18 months after treatment, and three onychomycosis patients were all cured in other two reports. The therapeutic effect of PDT for one pityriasis versicolor patient was also reported (Qiao et al., 2010).

Six Korean patients aged 23-47 years with recalcitrant Malassezia folliculitis were enrolled in a clinical PDT trial employing methyl 5-aminolevulinic acid (MAL)-PDT. These patients were offered MAL-PDT as an alternative treatment option due to inability or nephrotoxicity to tolerate oral antifungals. MAL was applied locally as a cream to each lesion (located on the patients' trunks) and covered with an adhesive occlusive dressing polyurethane film. After $3 \mathrm{~h}$, the cream was wiped off and illumination was performed immediately thereafter with non-coherent red light using light emitting diodes (wavelength $630 \mathrm{~nm}$, light dose $37 \mathrm{~J} / \mathrm{cm}^{2}$ ). Patients underwent three sessions of MAL-PDT at 2-week intervals. One month after the last PDT treatment, patients returned to the hospital and lesions were photographed (Lee et al., 2010). After three sessions of MAL-PDT, inflammatory lesions had decreased and improved obviously in four patients, had improved slightly in one patient, and had not improved in one patient.

Photodynamic therapy has been studied to treat ophthalmological disease secondary to fungal infection of the eyes. The efficacy and safety of PDT was evaluated in the long-term control of subfoveal CNV associated with toxoplasmic retinochoroiditis (Neri et al., 2010). The records of 13 patients with classic subfoveal CNV associated with toxoplasmic retinochoroiditis treated with PDT were reviewed. All patients were followed up for at least 48 months. Postoperative visual acuity (VA) was defined as a gain or loss of two or more lines of best-corrected visual acuity (BCVA), respectively. Post-treatment CNV size was dichotomized into "increased" if the major CNV diameter (CMD) had increased by $\geq 300 \mathrm{mM}$, and as "stable/reduced" if it had decreased by $\geq 300 \mathrm{mM}$ or had not changed by $>300 \mathrm{mM}$. At the 48 -month follow-up, all patients had stable/improved BCVA and a mean stable/reduced CMD $(846 \pm 326.5 \mathrm{mM})$, with the BCVA having improved significantly $(p<0.0001)$ from $0.29 \pm 0.19$ at baseline to $0.54 \pm 0.16$ at 48 months. Finally, a 28 -year-old one-eyed woman with subretinal CNV in the right eye of due to C. endophthalmitis was treated with a combination of PDT and drugs. The CNV was treated with six PDT sessions with verteporfin in association with systemic steroid therapy with prednisone $(100 \mathrm{mg}$ /day to reduce) and fluconazole ( $800 \mathrm{mg} /$ day to reduce). VA was assessed in pre-PDT conditions and after six PDT treatments (24 months of follow-up; Tedeschi et al., 2007).

\section{FORMULATION OF NEW CONCEPTS, CONCLUSION}

Advances in microbial physiology continue to shed light on a series of pathways, components, and phenotypes that may serve as potential alternative and attractive targets for antimicrobial drug discovery. These approaches have revealed novel molecular mechanisms responsible for cooperation among cells and define new roles of population structure for the evolution of cooperative interactions. This knowledge of interaction parameters is changing the view of microbial processes, and suggests new ways to fight infection by exploiting social interaction (Xavier, 2011). Targeting bacterial virulence factors is also a novel approach under investigation for the development of new antimicrobials that can be used to disarm pathogens in the host (Lee et al., 2003). The broadspectrum activity and the non-specific action of APDI should be further explored to address these biological phenomena. There is no documented evidence whether PDT can disrupt these sophisticated microbial defensive lines. We have to take into account that PDI is able to eradicate microorganisms without discriminating resistant isolates, both planktonic and biofilm species. This is in concert with the potential of localized photooxidative stress to inactivate virulence factors (Kömerik et al., 2000; Tubby et al., 2009) and virulence determinants (Zolfaghari et al., 2009; Hamblin et al., 2011; Sharma et al., 2011) in the absence of any documented conventional resistance mechanism. The possibility of active efflux seems to be related with some but not all the molecular classes of PS although improved delivery methods may overcome this barrier. A summary of promising, state of the art, powerful PDI-based combinations is provided in Table 1.

Nanoparticles can be engineered as sophisticated drug delivery vehicles to carry various therapeutic or diagnostic agents and are potentially useful for medical applications including targeted drug delivery, gene therapy, and cell labeling (Kim et al., 2010). PDT has also attracted the interest of nanotechnology as the effectiveness of the treatment can be greatly enhanced by the use of nanoparticles. In the last decade, different approaches to the combination of nanoparticles and PDT have been investigated in relation to the antimicrobial applications of the technique. One use of the nanoparticles is to improve the delivery of PS to bacteria; others use the nanoparticles to improve the inactivation kinetics (Perni et al., 2011). Many of the PS being studied for PDI of bacteria are based on the tetrapyrrole nucleus are lipophilic and readily aggregate in aqueous solution, resulting in the loss of photosensitizing activity (Sibani et al., 2008; Engelhardt et al., 2010). To overcome this problem, suitable PS carriers were designed to deliver PS, e.g., liposomes, (Ferro et al., 2006; Bombelli et al., 2008; Engelhardt et al., 2010) micelles, (Tsai et al., 2009), and nanoparticles (Schwiertz et al., 2009; Guo et al., 2010). Amongst these systems, liposomes are most commonly employed to incorporate lipophilic PS, and have been proved to enhance the APDI of various PS, not only because liposomes increase the solubility and stability of PS, but also because they can facilitate the penetration of PS into bacteria by means of fusion processes or disturbing the cell walls (Jia et al., 2010). However, these reported liposomal formulations mainly aimed to deliver PS passively, while little research was done to apply actively targeted liposomes in the PDI of bacteria or fungi (Mccarron et al., 2007). An interesting application describes the use of a patch as a mucoadhesive drug delivery TBO system 
Table 1 | Photodynamic therapy-based combinations: potential antifungal countermeasures.

\begin{tabular}{|c|c|c|c|c|}
\hline PDT-combinations & Synergist & Fungal species & Target(s) & Reference \\
\hline \multirow[t]{2}{*}{ Polycationic conjugates of chlorin } & Visible light & C. albicans & non-specific reactive & Tegos et al. (2006) \\
\hline & & & oxygen species (ROS) & \\
\hline Methylene blue (MB), tolouidine blue (TBO) & Visible light, EPIs & C. albicans & ROS & Prates et al. (2011) \\
\hline $\mathrm{MB}$ & Visible light, azoles & C. albicans & ROS & Snell et al. (2011) \\
\hline Functionalized C60-fullerene & Visible light & C. albicans & ROS & Lu et al. (2010) \\
\hline PEI-ce6 & Saponins visible light & C. albicans & ROS & Coleman et al. (2010) \\
\hline PEI-ce6 & Caspofungin-visible light & C. neoformans & Membrane & Fuchs et al. (2007b) \\
\hline
\end{tabular}

(Donnelly et al., 2007). However, the concentrations of TBO in the receiver compartments separated from patches by membranes intended to mimic biofilm structures were an order of magnitude below those inducing high levels of kill, even after $6 \mathrm{~h}$ release.

Photodynamic therapy is not a conventional drug discovery platform since three elements (PS, visible light, and oxygen) are essential for successful deployment. As infection involves both the pathogen and the host, it is important to exploit this additional complexity in PDT ventures. The evaluation of the naturally occurring pigment curcumin (Martins et al., 2009) against C. albicans provides an example. Planktonic, biofilm cells as well as macrophages were submitted to the same photodynamic conditions to investigate whether the treatment could be toxic to microbial as well as mammalian cells and identify a therapeutic window for preclinical development. On the other hand, antimicrobial PDT treatment has been shown to be potently and functionally inactivated by IL-1 beta and TNF-alpha (Braham et al., 2009).

Researchers have bypassed some of the difficulties associated with new antimicrobial development by developing tractable whole-animal screens that utilize the well-studied nematode Caenorhabditis elegans, the great wax moth Galleria mellonella, and the fruit fly Drosophila melanogaster as model hosts to identify and develop new classes of antimicrobial agents with antivirulence or immunomodulatory efficacy and evaluate toxicity or efficacy. The amenability of these non-vertebrate hosts to large screens has made these model hosts useful to identify or develop active compounds against either bacterial or fungal pathogens (Apidianakis et al., 2007, 2011; Fuchs et al., 2010). Therefore, the design of host-pathogen studies exploring the ability of PDT to interfere with virulence determinants requires sophisticated tools and approaches. The recent example of a host-parasite model to assess intracellular targeting specificity of novel phthalocyanines (Dutta et al., 2011) will inspire similar explorations.

\section{REFERENCES}

Abruzzo, G., Flattery, A. M., Gill, C. J., Kong, L., Smith, J. G., Pikounis, V. B., Balkovec, J. M., Bouffard, A. F., Dropinski, J. F., Rosen, H, Kropp, H, and Bartizal, K. (1997). Evaluation of the echinocandin antifungal MK-0991 (L-743,872): efficaecies in mouse models of disseminanted aspergillosis, candidiasis and cryptococcosis. Antimicrob. Agents Chemother. 41, 2333-2338.
Alanio, A., Desnos-Ollivier, M., and Dromer, F. (2011). Dynamics of Cryptococcus neoformans-macrophage interactions reveal that fungal background influences outgoencephalitis in humans. MBio 2, e00158-11.

Ameen, M. A. R. (2009). Developments in the management of mycetomas. Clin. Exp. Dermatolol. 32, $1-7$. come during cryptococcal menin-

A brief comparison between antibacterial and antifungal PDT, reveals that the latter require higher concentrations of PS $(1 \mu \mathrm{M}$ minimum and generally higher) for substantial fungal PDI. This fact translates into the need to use considerably higher PS concentrations for potential in vivo antifungal applications. It should also be noted that fungal BSI often arise from local infections that spread systemically. PDT has the particular advantage of rapidly reducing numbers of viable fungal cells allowing antifungal drugs time to work. This notion supports the argument that PDT is ideal for localized infections but it also may be prophylactic to prevent the development of BSI or may be extremely useful in combinatorial implementation with antifungals. This therapeutic concept has been demonstrated in practice by employing PDT combined with antibiotics in animal models of localized infections caused by Gram-negative bacteria (Lu et al., 2010).

Further clinical trials are needed to evaluate the efficacy of PDT to treat superficial mycoses. It is also important to optimize treatment protocols in order to cope with recurrence. PDT may be an effective treatment option for patients with recalcitrant fungal infections. However, the available clinical data are still limited, and additional controlled trials including multiple patients will be necessary to verify the results of the promising pilot studies.

\section{ACKNOWLEDGMENTS}

George P. Tegos is supported by the NIH (grant 5U54MH08469002). Research conducted in the Hamblin Laboratory was supported by NIH (RO1 AI050875 to MRH) and US Air Force MFEL Program (FA9550-04-1-0079). Research conducted in the Mylonakis Laboratory was supported by NIH (RO1 AI050875 to Eleftherios Mylonakis) and. Tianhong Dai was partially supported by a Bullock-Wellman Fellowship Award and an Airlift Research Foundation Extremity Trauma Research Grant (grant 109421). Research conducted by Tyler G. St. Denis is supported by the Columbia University I. I. Rabi Fellows Program.

Apidianakis, Y., Mindrinos, M. N., Xiao, W., Tegos, G. P., Papisov, M. I., Hamblin, M. R., Davis, R. W., Tompkins, R. G., and Rahme, L. G. (2007). Involvement of skeletal muscle gene regulatory network in susceptibility to wound infection following trauma. PLoS ONE 2, e1356. doi:10.1371/journal.pone.0001356

Apidianakis, Y., Que, Y.-A., Xu, W., Tegos, G. P., Zimniak, P., Hamblin, M. R., Tompkins, R. G., Xiao,
W., and Rahme, L. G. (2011). Down-regulation of glutathione Stransferase alpha 4 (hGSTA4) in the muscle of thermally injured patients is indicative of susceptibility to bacterial infection. FASEB J. 2, 730-737.

Bertoloni, G., Reddi, E., Gatta, M., Burlini, C., and Jori, G. (1989). Factors influencing the haematoporphyrin-sensitized photoinactivation of Candida albicans. J. Gen. Microbiol. 135, 957-966. 
Bertoloni, G., Rossi, F., Valduga, G., Jori, G., Ali, H., and Van Lier, J. E. (1992). Photosensitizing activity of water- and lipid-soluble phthalocyanines on prokaryotic and eukaryotic microbial cells. Microbios 71, 33-46.

Biel, M. (2010). Photodynamic therapy of bacterial and fungal biofilm infections. Methods Mol. Biol. 635, 175-194.

Bisland, S., Chien, C., Wilson, B. C., and Burch, S. (2006). Pre-clinical in vitro and in vivo studies to examine the potential use of photodynamic therapy in the treatment of osteomyelitis. Photochem. Photobiol. Sci. 5, 31-38.

Bliss, J. M., Bigelow, C. E., Foster, T. H., and Haidaris, C. G. (2004). Susceptibility of Candida species to photodynamic effects of photofrin. Antimicrob. Agents Chemother. 48, 2000-2006.

Bombelli, C., Bordi, F., Ferro, S., Giansanti, L., Jori, G., Mancini, G., Mazzuca, C., Monti, D., Ricchelli, F., Sennato, S., and Venanzi, M. (2008). New cationic liposomes as vehicles of mtetrahydroxyphenylchlorin in photodynamic therapy of infectious diseases. Mol. Pharm. 5, 672-679.

Braham, P., Herron, C., Street, C., and Darveau, R. (2009). Antimicrobial photodynamic therapy may promote periodontal healing through multiple mechanisms. J. Periodontol. 80, 1790-1798.

Brizendine, K. P., and Pappas, P. G. (2010). Cryptococcal meningitis: current approaches to management in patients with and without AIDS. Curr. Infect. Dis. Rep. 12, 299-305.

Brombacher, K., Fischer, B. B., Rüfenacht, K., and Eggen, R. I. (2006). The role of Yaplp and Skn7pmediated oxidative stress response in the defence of Saccharomyces cerevisiae against singlet oxygen. Yeast 23, 741-750.

Calzavara-Pinton, P. G., Venturini, M., and Sala, R. (2005). A comprehensive overview of photodynamic therapy in the treatment of superficial fungal infections of the skin. J. Photochem. Photobiol. B Biol. 78, 1-6.

Cannon, R. D., Lamping, E., Holmes, A. R., Niimi, K., Baret, P. V., Keniya, M. V., Tanabe, K., Niimi, M., Goffeau, A., and Monk, B. C. (2009). Effluxmediated antifungal drug resistance. Clin. Microbiol. Rev. 22, 291-321.

Caston-Osorio, J. A., Rivero, A., and Torre-Cisneros, J. (2008). Epidemiology of invasive fungal infection. Int. J. Antimicrob. Agents 32(Suppl. 2), S103-S109.
Chabrier-Roselló, Y., Foster, T. H., Mitra, S., and Haidaris, C. G. (2008). Respiratory deficiency enhances the sensitivity of the pathogenic fungus Candida to photodynamic treatment. Photochem. Photobiol. 84, 1141-1148.

Chabrier-Rosello, Y., Foster, T. H., PerezNazario, N., Mitra, S., and Haidaris, C. G. (2005). Sensitivity of Candida albicans germ tubes and biofilms to photofrin-mediated phototoxicity. Antimicrob. Agents Chemother. 49, 4288-4295.

Chabrier-Roselló, Y., Giesselman, B. R., De Jesús-Andino, F. J., Foster, T. H., Mitra, S., and Haidaris, C. G. (2010). Inhibition of electron transport chain assembly and function promotes photodynamic killing of Candida. J. Photochem. Photobiol. B Biol. 99, 117-125.

Chandra, J., Kuhn, D. M., Mukherjee, P. K., Hoyer, L. L., Mccormick, T., and Ghannoum, M. A. (2001). Biofilm formation by the fungal pathogen Candida albicans: development, architecture, and drug resistance. $J$. Bacteriol. 183, 5385-5394.

Coleman, J., Okoli, I., Tegos, G. P., Holson, E. B., Wagner, F. F., Hamblin, M. R., and Mylonakis, E. (2010). Characterization of plant-derived saponin natural products against Candida albicans. ACS Chem. Biol. 5, 321-332.

Costa, A., De Campos Rasteiro, V. M., Pereira, C. A., Da Silva Hashimoto, E. S, Beltrame, M. Jr., Junqueira, J. C., and Jorge, A. O. (2011). Susceptibility of Candida albicans and Candida dubliniensis to erythrosine- and LED-mediated photodynamic therapy. Arch. Oral Biol. 56, 1299-1305.

Costa, A., Rasteiro, V. M., Pereira, C. A., Rossoni, R. D., Junqueira, J. C., and Jorge, A. O. (2012). The effects of rose bengal- and erythrosinemediated photodynamic therapy on Candida albicans. Mycoses 55, 56-63.

Crump, J., and Collignon, P. J. (2000). Intravascular catheter-associated infections. Eur. J. Clin. Microbiol. Infect. Dis. 19, 1-8.

Dai, T., Bil, D. E., Arce, V. J., Tegos, G. P., and Hamblin, M. R. (2011a). Blue dye and red light, a dynamic combination for prophylaxis and treatment of cutaneous Candida albicans infections in mice. Antimicrob. Agents Chemother. 55, 5710-5717.

Dai, T., Kharkwal, G. B., Tanaka, M., Huang, Y. Y., Bil De Arce, V. J., and Hamblin, M. R. (2011b). Animal models of external traumatic wound infections. Virulence 2, 296-315.
Donnelly, R., Mccarron, P. A., Tunney, M. M., and David Woolfson, A. (2007). Potential of photodynamic therapy in treatment of fungal infections of the mouth. Design and characterisation of a mucoadhesive patch containing toluidine blue $O$. J. Photochem. Photobiol. B Biol. 86, 59-69.

Donnelly, R. F., Mccarron, P. A. Lightowler, J. M., and Woolfson, A. D. (2005). Bioadhesive patch-based delivery of 5-aminolevulinic acid to the nail for photodynamic therapy of onychomycosis. J. Control Release. 103, 381-392.

Dovigo, L., Pavarina, A. C., Mima, E. G., Giampaolo, E. T., Vergani, C. E., and Bagnato, V. S. (2011a). Fungicidal effect of photodynamic therapy against fluconazole-resistant Candida albicans and Candida glabrata. Mycoses 54, 123-130.

Dovigo, L., Pavarina, A. C., Carmello, J. C., Machado, A. L., Brunetti, I. L., and Bagnato, V. S. (2011b). Susceptibility of clinical isolates of Candida to photodynamic effects of curcumin. Lasers Surg. Med. 43, 927-934.

D’Souza, C., Kronstad, J. W., Taylor, G., Warren, R., Yuen, M., Hu, G., Jung, W. H., Sham, A., Kidd, S. E., Tangen, K., Lee, N., Zeilmaker, T., Sawkins, J., Mcvicker, G., Shah, S., Gnerre, S., Griggs, A., Zeng, Q., Bartlett, K., Li, W., Wang, X., Heitman, J., Stajich, J. E., Fraser, J. A., Meyer, W., Carter, D., Schein, J., Krzywinski, M., Kwon-Chung, K. J., Varma, A., Wang, J., Brunham, R., Fyfe, M. Ouellette, B. F., Siddiqui, A., Marra, M., Jones, S., Holt, R., Birren, B. W. Galagan, J. E., and Cuomo, C. A. (2011). Genome variation in Cryptococcus gattii, an emerging pathogen of immunocompetent hosts. MBio 2, e00342.

Dutta, S., Ongarora, B. G., Li, H., Vicente Mda, G., Kolli, B. K., and Chang, K. P. (2011). Intracellular targeting specificity of novel phthalocyanines assessed in a host-parasite model for developing potential photodynamic medicine. PLoS ONE 6, e20786. doi:10.1371/journal.pone.0020786

Ehrenshaft, M., Jenns, A. E., Chung, K. R., and Daub, M. E. (1998). SOR1, a gene required for photosensitizer and singlet oxygen resistance in Cercospora fungi, is highly conserved in divergent organisms. Mol. Cell 1, 603-609.

Engelhardt, V., Krammer, B., and Plaetzer, K. (2010). Antibacterial photodynamic therapy using watersoluble formulations of hypericin or mTHPC is effective in inactivation of Staphylococcus aureus. Photochem. Photobiol. Sci. 9, 365-369.

Espinel-Ingroff, A. (1998). Comparison of in vitro activities of the new triazole SCH56592 and the echinocandins MK-0991 (L743, 872) and LY303366 against opportunistic filamentous and dimorphic fungi and yeasts. J. Clin. Microbiol. 36, 2950-2956.

Feldmesser, M., Kress, Y., Mednick, A., and Casadevall, A. (2000). The effect of the echinocandin analogue caspofungin on cell wall glucan synthesis by Cryptococcus neoformans. J. Infect. Dis. 182, 1791-1795.

Ferro, S., Ricchelli, F., Mancini, G., Tognon, G., and Jori, G. (2006). Inactivation of methicillin resistant Staphylococcus aureus (MRSA) by liposome-delivered photosensitising agents. J. Photochem. Photobiol. B Biol. 83, 98-104.

Foley, J. W., Song, X., Demidova, T. N., Jalil, F., and Hamblin, M. R. (2006). Synthesis and properties of benzo[a]phenoxazinium chalcogen analogues as novel broad-spectrum antimicrobial photosensitizers. J. Med. Chem. 49, 5291-5299.

Fontana, C., Abernethy, A. D., Som, S., Ruggiero, K., Doucette, S., Marcantonio, R. C., Boussios, C. I., Kent, R., Goodson, J. M., Tanner, A. C., and Soukos, N. S. (2009). The antibacterial effect of photodynamic therapy in dental plaque-derived biofilms. J. Periodont. Res. 44, 751-759.

Foote, C. S. (1991). Definition of type I and type II photosensitized oxidation. Photochem. Photobiol. 54, 659.

Friedberg, J., Skema, C., Baum, E. D., Burdick, J., Vinogradov, S. A., Wilson, D. F., Horan, A. D., and Nachamkin, I. (2001). In vitro effects of photodynamic therapy on Aspergillus fumigatus. J. Antimicrob. Chemother. 48, 105-107.

Frimannsson, D. O., Grossi, M., Murtagh, J., Paradisi, F., and O'Shea, D. F. (2010). Light induced antimicrobial properties of a brominated boron difluoride $(\mathrm{BF}(2))$ chelated tetraarylazadipyrromethene photosensitizer. J. Med. Chem. 53, 7337-7343.

Fuchs, B., O'Brien, E., Khoury, J. B., and Mylonakis, E. (2010). Methods for using Galleria mellonella as a model host to study fungal pathogenesis. Virulence 1, 475-482.

Fuchs, B., Tang, R. J., and Mylonakis, E. (2007a). The temperature-sensitive role of Cryptococcus neoformans ROM2 in cell morphogenesis. PLoS ONE 2, e368. doi:10.1371/journal.pone. 0000368 
Fuchs, B., Tegos, G. P., Hamblin, M. R., and Mylonakis, E. (2007b). Susceptibility of Cryptococcus neoformans to photodynamic inactivation is associated with cell wall integrity. Antimicrob. Agents Chemother. 51, 2929-2936.

Gasparetto, A., Lapinski, T. F., Zamuner, S. R., Khouri, S., Alves, L. P., Munin, E., and Salvador, M. J. (2010). Extracts from Alternanthera maritima as natural photosensitizers in photodynamic antimicrobial chemotherapy (PACT). J. Photochem. Photobiol. B Biol. 99, 15-20.

Gavalda, J., Len, O., San Juan, R., Aguado, J., Fortun, J., Lumbreras, C., Moreno, A., Munoz, P., Blanes, M., Ramos, A., Rufi, G., Gurgui, M., Torre-Cisneros, T., Montejo, M., Cuenca-Estrella, M., RodriguezTudela, J., Pahissa, A., and RESITRA (Spanish Network for Research on Infection in Transplantation). (2005). Risk factors for invasive aspergillosis in solid-organ transplant recipients: a case-control study. Clin. Infect. Dis. 41, 52-59.

Gerik, K., Bhimireddy, S. R., Ryerse, J. S., Specht, C. A., and Lodge, J. K. (2008). PKCl is essential for protection against both oxidative and nitrosative stresses, cell integrity, and normal manifestation of virulence factors in the pathogenic fungus Cryptococcus neoformans. Eukaryot. Cell 7, 1685-1698.

Gilaberte, Y., Aspiroz, C., Martes, M. P., Alcalde, V., Espinel-Ingroff, A., and Rezusta, A. (2011). Treatment of refractory fingernail onychomycosis caused by nondermatophyte molds with methylaminolevulinate photodynamic therapy. J. Am. Acad. Dermatol. 65, 669-671.

Giroldo, L., Felipe, M. P., De Oliveira, M. A., Munin, E., Alves, L. P., and Costa, M. S. (2009). Photodynamic antimicrobial chemotherapy (PACT) with methylene blue increases membrane permeability in Candida albicans. Lasers Med. Sci. 24, 109-112.

Giuliani, F., Martinelli, M., Cocchi, A., Arbia, D., Fantetti, L., and Roncucci, G. (2010). In vitro resistance selection studies of RLP068/Cl, a new $\mathrm{Zn}$ (II) phthalocyanine suitable for antimicrobial photodynamic therapy. Antimicrob. Agents Chemother. 54, 637-642.

Gonzales, F., Da Silva, S. H., Roberts, D. W., and Braga, G. U. (2010). Photodynamic inactivation of conidia of the fungi Metarhizium anisopliae and Aspergillus nidulans with methylene blue and toluidine blue. Photochem. Photobiol. 86, 653-661.
Gonzales, F., and Maisch, T. (2012). Photodynamic inactivation for controlling Candida albicans infections. Fungal Biol. 116, 1-10.

Gudlaugsson, O., Gillespie, S., Lee, K., Vande, Berg, J., Hu, J., Messer, S., Herwaldt, L., Pfaller, M., and Diekema, D. (2003). Attributable mortality of nosocomial candidemia, revisited. Clin. Infect. Dis. 37, 1172-1177.

Guo, Y., Rogelj, S., and Zhang, P. (2010). Rose bengal-decorated silica nanoparticles as photosensitizers for inactivation of Gram-positive bacteria. Nanotechnology 21, 065102.

Hamblin, M., Tegos, G. P., St. Denis, T., and Huang, L. (2011). Antimicrobial photodynamic therapy: can resistance develop? Photodiagnosis Photodyn. Ther. 8, 178.

Harris, F., Chatfield, L. K., and Phoenix, D. A. (2005). Phenothiazinium based photosensitisers - photodynamic agents with a multiplicity of cellular targets and clinical applications. Curr. Drug Targets 6, 615-627.

Holmes, A. R., Lin, Y. H., Niimi, K., Lamping, E., Keniya, M., Niimi, M., Tanabe, K., Monk, B. C., and Cannon, R. D. (2008). ABC transporter Cdrlp contributes more than $\mathrm{Cdr} 2 \mathrm{p}$ does to fluconazole efflux in fluconazole-resistant Candida albicans clinical isolates. Antimicrob. Agents Chemother. 52, 3851-3862.

Holmes, A. R., Tsao, S., Ong, S. W., Lamping, E., Niimi, K., Monk, B. C., Niimi, M., Kaneko, A., Holland, B. R., Schmid, J., and Cannon, R. D. (2006). Heterozygosity and functional allelic variation in the Candida albicans efflux pump genes CDR1 and CDR2. Mol. Microbiol.62, 170-186.

Horn, D., Neofytos, D., Anaissie, E., Fishman, J., Steinbach, W., Olyaei, A., Marr, K., Pfaller, M., and Chang, C., and Webster, K. (2009). Epidemiology and outcomes of candidemia in 2019 patients: data from the prospective antifungal therapy alliance registry. Clin. Infect. Dis. 48, 1695-1703.

Huang, L., Huang, Y. Y., Mroz, P., Tegos, G. P., Zhiyentayev, T., Sharma, S. K., Lu, Z., Balasubramanian, T., Krayer, M., Ruzie, C., Yang, E., Kee, H. L., Kirmaier, C., Diers, J. R., Bocian, D. F., Holten, D., Lindsey, J. S., and Hamblin, M. R. (2010a). Stable synthetic cationic bacteriochlorins as selective antimicrobial photosensitizers. Antimicrob. Agents Chemother. 54, 3834-3841.

Huang, L., Terakawa, M., Zhiyentayev, T., Huang, Y. Y., Sawayama, Y.,
Jahnke, A., Tegos, G. P., Wharton, T., and Hamblin, M. R. (2010b). Innovative cationic fullerenes as broadspectrum light-activated antimicrobials. Nanomedicine 6, 442-452.

Hunt, D. W. (2002). Rostaporfin (Miravant Medical Technologies). Idrugs 5, 180-186.

Jia, Y., Joly, H., and Omri, A. (2010). Characterization of the interaction between liposomal formulations and Pseudomonas aeruginosa. J. Liposome Res. 20, 134-146.

Kamp, H., Tietz, H. J., Lutz, M., Piazena, H., Sowyrda, P., Lademann, J., and Blume-Peytavi, U. (2005). Antifungal effect of 5-aminolevulinic acid PDT in Trichophyton rubrum. Mycoses 48, 101-107.

Kim, B., Rutka, J. T., and Wchan, W. C. W. (2010). Nanomedicine. New Engl. J. Med. 363, 2434-2443.

Kömerik, N., Wilson, M., and Poole, S. (2000). The effect of photodynamic action on two virulence factors of Gram-negative bacteria. Photochem. Photobiol. 72, 676-680.

Kronstad, J. W., Attarian, R., Cadieux, B., Choi, J., D'Souza, C. A., Griffiths, E. J., Geddes, J. M., Hu, G., Jung, W. H., Kretschmer, M., Saikia, S., and Wang, J. (2011). Expanding fungal pathogenesis: Cryptococcus breaks out of the opportunistic box. Nat. Rev. Microbiol. 9, 193-203.

Kumar, S., and Kimball, A. B. (2009). New antifungal therapies for the treatment of onychomycosis. Expert Opin. Investig. Drugs 18, 727-734.

Lafleur, M., Kumamoto, C. A., and Lewis, K. (2006). Candida albicans biofilms produce antifungaltolerant persister cells. Antimicrob. Agents Chemother. 50, 3839-3846.

Lafleur, M., Qi, Q., and Lewis, K. (2010). Patients with long-term oral carriage harbor high-persister mutants of Candida albicans. Antimicrob. Agents Chemother. 54, 39-44.

Lam, M., Jou, P. C., Lattif, A. A., Lee, Y., Malbasa, C. L., Mukherjee, P. K. Oleinick, N. L., Ghannoum, M. A., Cooper, K. D., and Baron, E. D. (2011). Photodynamic therapy with Pc 4 induces apoptosis of Candida albicans. Photochem. Photobiol. 87, 904-909.

Lambrechts, S., Aalders, M. C., and Van Marle, J. (2005). Mechanistic study of the photodynamic inactivation of Candida albicans by a cationic porphyrin. Antimicrob. Agents Chemother. 49, 2026-2034.

Lamping, E., Baret, P. V., Holmes, A. R., Monk, B. C., Goffeau, A., and Cannon, R. D. (2010). Fungal PDR transporters: phylogeny, topology, motifs and function. Fungal Genet. Biol. 47, 127-142.

Lazarova, G. (1993). Effect of glutathione on rose bengal photosensitized yeast damage. Microbios 75, 39-43.

Leach, A. G., and Houk, K. N. (2002). Diels-Alder and ene reactions of singlet oxygen, nitroso compounds and triazolinediones: transition states and mechanisms from contemporary theory. Chem. Commun. (Camb.) 21, 1243-1255.

Lee, J., Kim, B. J., and Kim, M. N. (2010). Photodynamic therapy: new treatment for recalcitrant Malassezia folliculitis. Lasers Surg. Med. 42, 192-196.

Lee, Y., Almqvist, F., and Hultgren, S. J. (2003). Targeting virulence for antimicrobial chemotherapy. Curr. Opin. Pharmacol. 3, 513-519.

Lewis, K. (2001). Riddle of biofilm resistance. Antimicrob. Agents Chemother. 45, 999-1007.

Lewis, K. (2010). Persister cells. Annu. Rev. Microbiol. 64, 357-372.

Lu, Z., Dai, T., Huang, L., Kurup, D. B., Tegos, G. P., Jahnke, A., Wharton, T., and mHamblin, M. R. (2010). Photodynamic therapy with a cationic functionalized fullerene rescues mice from fatal wound infections. Nanomedicine (Lond.) 5, 1525-1533.

Lyon, J., Pedroso E Silva Azevedo Cde, M., Moreira, L. M., De Lima, C. J., and De Resende, M. A. (2011). Photodynamic antifungal therapy against chromoblastomycosis. Mycopathologia 172, 293-297.

Mang, T., Mikulski, L., and Hall, R. E. (2010). Photodynamic inactivation of normal and antifungal resistant Candida species. Photodiagnosis Photodyn. Ther. 7, 98-105.

Martins, C., Da Silva, D. L., Neres, A. T., Magalhães, T. F., Watanabe, G. A., Modolo, L. V., Sabino, A. A., De Fátima, A., and De Resende, M. A. (2009). Curcumin as a promising antifungal of clinical interest. $J$. Antimicrob. Chemother. 63, 337-339. Mccarron, P., Donnelly, R. F. Marouf, W, and Calvert, D. E. (2007). Anti-adherent and antifungal activities of surfactantcoated poly(ethylcyanoacrylate) nanoparticles. Int. J. Pharm. 340, 182-190.

Mima, E., Pavarina, A. C., Dovigo, L. N., Vergani, C. E., Costa, C. A., Kurachi, C., Bagnato, V.S. (2010). Susceptibility of Candida albicans to photodynamic therapy in a murine model of oral candidosis. Oral Surg. Oral Med. Oral Pathol. Oral Radiol. Endod. 109 392-401. 
Mitra, S., Haidaris, C. G., Snell, S. B., Giesselman, B. R., Hupcher, S. M., and Foster, T. H. (2011). Effective photosensitization and selectivity in vivo of Candida albicans by meso-tetra (N-methyl-4-pyridyl) porphine tetra tosylate. Lasers Surg. Med. 43, 324-332.

Mitton, D., and Ackroyd, R. (2008). A brief overview of photodynamic therapy in Europe. Photodiagnosis Photodyn. Ther. 5, 103-111.

Morgan, J. J. J., Zheng, X., Pandey, S. K., and Pandey, R. K. (2010). Substrate affinity of photosensitizers derived from chlorophyll-a: the ABCG2 transporter affects the phototoxic response of side population stem cell-like cancer cells to photodynamic therapy. Mol. Pharm. 5, 1789-1804.

Müller, P., Guggenheim, B., and Schmidlin, P. R. (2007). Efficacy of gasiform ozone and photodynamic therapy on a multispecies oral biofilm in vitro. Eur. J. Oral Sci. 115, 77-80.

Nakonieczna, J., Michta, E., Rybicka, M., Grinholc, M., Gwizdek-Wiśniewska, A., and Bielawski, K. P. (2010). Superoxide dismutase is upregulated in Staphylococcus aureus following protoporphyrin-mediated photodynamic inactivation and does not directly influence the response to photodynamic treatment. BMC Microbiol. 10, 323. doi:10.1186/1471-2180-10-323

Neofytos, D., Horn, D., Anaissie, E., Steinbach, W., Olyaei, A., Fishman, J., Pfaller, M., Chang, C., and Webster, K., and Marr, K. (2009). Epidemiology and outcome of invasive fungal infection in adult hematopoietic stem cell transplant recipients: analysis of multicenter prospective antifungal therapy (PATH) alliance registry. Clin. Infect. Dis. 48, 265-273.

Neri, P., Mercanti, L., Mariotti, C., Salvolini, S., and Giovannini, A. (2010). Long-term control of choroidal neovascularization in quiescent congenital toxoplasma retinochoroiditis with photodynamic therapy: 4-year results. Int. Ophthalmol. 30, 51-56.

Nitzan, Y., Gutterman, M., Malik, Z., and Ehrenberg, B. (1992). Inactivation of Gram-negative bacteria by photosensitized porphyrins. Photochem. Photobiol. 55, 89-96.

Ochsner, M. (1997). Photophysical and photobiological processes in the photodynamic therapy of tumours. J. Photochem. Photobiol. B Biol. 39, $1-18$.
Oriel, S., and Nitzan, Y. (2010). Photoinactivation of Candida albicans by its own endogenous porphyrins. Curr. Microbiol. 60, 117-123.

Ostrosky-Zeichner, L., Casadevall, A., Galgiani, J., Odds, F., and Rex, J. (2010). An insight into the antifungal pipeline: selected new molecules and beyond. Nat. Rev. Drug Discov. 9, 719-727.

Ozaki, K., Tanaka, K., Imamura, H., Hihara, T., Kameyama, T., Nonaka, H., Hirano, H., Matsuura, Y., and Takai, Y. (1996). Romlp and Rom2p are GDP/GTP exchange proteins (GEPs) for Rholp small GTP binding proteins in Saccharomyces cerevisiae. EMBO J. 15, 2196-2207.

Paardekooper, M., Van Den Broek, P. J., De Bruijne, A. W., Elferink, J. G., Dubbelman, T. M., and Van Steveninck, J. (1992). Photodynamic treatment of yeast cells with the dye toluidine blue: all-or-none loss of plasma membrane barrier properties. Biochim. Biophys. Acta 1108, 86-90.

Pappas, P., Kauffman, C., Andes, D., Benjamin, D. Jr, Calandra, T., Edwards, J. Jr, Filler, S., Fisher, J., Kullberg, B., Ostrosky-Zeichner, L., Reboli, A., Rex, J., Walsh, T., Sobel, J., and Infectious Diseases Society of America. (2009). Clinical practice guidelines for the management of candidiasis: 2009 update by the Infectious Diseases Society of America. Clin. Infect. Dis. 48, 503-535.

Park, B., Wannemuehler, K. A., Marston, B. J., Govender, N., Pappas, P. G., and Chiller, T. M. (2009). Estimation of the current global burden of cryptococcal meningitis among persons living with HIV/AIDS. AIDS 23, 525-530.

Pereira, C., Romeiro, R. L., Costa, A. C., Machado, A. K., Junqueira, J. C., and Jorge, A. O. (2011). Susceptibility of Candida albicans, Staphylococcus aureus, and Streptococcus mutans biofilms to photodynamic inactivation: an in vitro study. Lasers Med. Sci. 26, 341-348.

Perni, S., Prokopovich, P., Pratten, J., Parkin, I. P., and Wilson, M. (2011). Nanoparticles: their potential use in antibacterial photodynamic therapy. Photochem. Photobiol. Sci. 10, 712-720.

Pfaller, M., Andes, D., Diekema, D., Espinel-Ingroff, A., Sheehan, D., and The Clsi Subcommittee for Antifungal Susceptibility Testing. (2010). Wild-type MIC distributions, epidemiological cutoff values and species-specific clinical breakpoints for fluconazole and Candida: time for harmonization of CLSI and
EUCAST broth microdilution methods. Drug Resist. Updat. 13, 180-195.

Pflumm, M. (2011). Caught on film. Nat. Med. 17, 650-653.

Philip, B., and Levin, D. E. (2001). Wsc1 and Mid2 are cell surface sensors for cell wall integrity signaling that act through Rom2, a guanine nucleotide exchange factor for Rho1. Mol. Cell. Biol. 21, 271-280.

Prates, R., Kato, I. T., Ribeiro, M. S., Tegos, G. P., and Hamblin, M. R R. (2011). Influence of multidrug efflux systems on methylene bluemediated photodynamic inactivation of Candida albicans. J. Antimicrob. Chemother. 66, 1525-1532.

Qiao, J., Li, R., Ding, Y., and Fang, H. (2010). Photodynamic therapy in the treatment of superficial mycoses: an evidence-based evaluation. Mycopathologia 170, 339-343.

Raab, O. (1900). Ueber diewirkung fluoreszierender stoffe auf infusori. $Z$. Biol. 39, 524-536.

Raghavendra, M., Koregol, A., and Bhola, S. (2009). Photodynamic therapy: a targeted therapy in periodontics. Aust. Dent. J. 54(Suppl. 1), S102-S109.

Rentz, A., Halpern, M. T., and Bowden, R. (1998). The impact of candidemia on length of hospital stay, outcome, and overall cost of illness. Clin. Infect. Dis. 27, 781-788.

Schuckert, K., Jopp, S., and Muller, U. (2006). De novo grown bone on exposed implant surfaces using photodynamic therapy and recombinant human bone morphogenetic protein-2: case report. Implant Dent. $15,361-365$.

Schwiertz, J., Wiehe, A., Grafe, S., Gitter, B., and Epple, M. (2009). Calcium phosphate nanoparticles as efficient carriers for photodynamic therapy against cells and bacteria. Biomaterials 30, 3324-3331.

Sharma, S., Dai, T., Kharkwal, G. B., Huang, Y. Y., Huang, L., De Arce, V. J., Tegos, G. P., and Hamblin, M. R. (2011). Drug discovery of antimicrobial photosensitizers using animal models. Curr. Pharm. Des. 17, 1303-1319.

Sibani, S., Mccarron, P. A., Woolfson, A. D., and Donnelly, R. F. (2008). Photosensitiser delivery for photodynamic therapy. Part 2: systemic carrier platforms. Expert Opin. Drug Deliv. 5, 1241-1254.

Simons, V., Morrissey, J. P., Latijnhouwers, M., Csukai, M., Cleaver, A. Yarrow, C., and Osbourn, A. (2006). Dual effects of plant steroidal alkaloids on Saccharomyces cerevisiae. Antimicrob. Agents Chemother. 50, 2732-2740.
Singleton, D. A., Hang, C., Szymanski, M. J., Meyer, M. P., Leach, A. G., Kuwata, K. T., Chen, J. S., Greer, A., Foote, C. S., and Houk, K. N. (2003). Mechanism of ene reactions of singlet oxygen. A two-step no-intermediate mechanism. J. Am. Chem. Soc. 125, 1319-1328.

Smijs, T., Bouwstra, J. A., Talebi, M., and Pavel, S. (2007). Investigation of conditions involved in the susceptibility of the dermatophyte Trichophyton rubrum to photodynamic treatment. J. Antimicrob. Chemother. $60,750-759$.

Smijs, T., Mulder, A. A., Pavel, S., Onderwater, J. J., Koerten, H. K., and Bouwstra, J. A. (2008). Morphological changes of the dermatophyte Trichophyton rubrum after photodynamic treatment: a scanning electron microscopy study. Med. Mycol. $46,315-325$.

Smijs, T., and Pavel, S. (2011). The susceptibility of dermatophytes to photodynamic treatment with special focus on Trichophyton rubrum. Photochem. Photobiol. 87, 2-13.

Smijs, T. G., Pavel, S., Talebi, M., and Bouwstra, J. A. (2009). Preclinical studies with 5,10,15-tris(4-methylpyridinium)20-phenyl-[21H,23H]-porphine trichloride for the photodynamic treatment of superficial mycoses caused by Trichophyton rubrum. Photochem. Photobiol. 85, 733-739.

Snell, S., Foster, T. H., and Haidaris, C. G. (2011). miconazole induces fungistasis and increases killing of Candida albicans subjected to photodynamic therapy. Photochem. Photobiol. doi:10.1111/j.1751-1097. 2011.01039.x [Epub ahead of print].

So, C., Tsang, P. W., Lo, P. C., Seneviratne, C. J., Samaranayake, L. P., and Fong, W. P. (2010). Photodynamic inactivation of Candida albicans by BAM-SiPc. Mycoses 53, 215-220.

Soares, B., Alves, O. A., Ferreira, M. V., Amorim, J. C., Sousa, G. R., Silveira Lde, B., Prates, R. A., Avila, T. V., Baltazar Lde, M., De Souza Dda, G., Santos, D. A., Modolo, L. V., Cisalpino, P. S., and Pinotti, M. (2011). Cryptococcus gattii: in vitro susceptibility to photodynamic inactivation. Photochem. Photobiol. 87, 357-364.

Soares, B., Da Silva, D. L., Sousa, G. R., Amorim, J. C., De Resende, M. A., Pinott, I. M., and Cisalpino, P. S. (2008). In vitro photodynamic inactivation of Candida spp. growth and adhesion to buccal epithelial cells. J. Photochem. Photobiol. B Biol. 94, 65-70. 
Sobel, J. (2007). Vulvovaginal candidosis. Lancet 369, 1961-1971.

Sotiriou, E., Koussidou-Eremonti, T., Chaidemenos, G., Apalla, Z., and Ioannides, D. (2010). Photodynamic therapy for distal and lateral subungual toenail onychomycosis caused by Trichophyton rubrum: preliminary results of a single-centre open trial. Acta Derm. Venereol. 90, 216-217.

Soukos, N., Chen, P. S., Morris, J. T., Ruggiero, K., Abernethy, A. D., Som, S., Foschi, F., Doucette, S., Bammann, L. L., Fontana, C. R., Doukas, A. G., and Stashenko, P. P. (2006). Photodynamic therapy for endodontic disinfection. J. Endod. 32, 979-984.

Souza, R., Junqueira, J. C., Rossoni, R. D., Pereira, C. A., Munin, E., and Jorge, A. O. (2010). Comparison of the photodynamic fungicidal efficacy of methylene blue, toluidine blue, malachite green and low-power laser irradiation alone against Candida albicans. Lasers Med. Sci. 25, 385-389.

St. Denis, T., Dai, T., Izikson, L., Astrakas, C., Anderson, R. R., Hamblin, M. R., and Tegos, G. P. (2011a). All you need is light: antimicrobial photoinactivation as an evolving and emerging discovery strategy against infectious disease. Virulence 2, 6 .

St. Denis, T., Huang, L., Dai, T., and Hamblin, M. R. (2011b). Analysis of the bacterial heat shock response to photodynamic therapy-mediated oxidative stress. Photochem. Photobiol. 87, 707-713.

Strakhovskaia, M., Belenikina, N. S., Ivanova, E. V., Chemeris, I. U. K., and Stranadko, E. F. (2002). The photodynamic inactivation of Candida guilliermondii in the presence of photodithazine. Mikrobiologiia 71, 349-353.
Takahashi, P., Toups, H. J., Greenberg, D. B., Dimopoullos, G. T., and Rusoff, L. L. (1975). Irradiation of Escherichia coli in the visible spectrum with a tunable organic-dye laser energy source. Appl. Microbiol. 29, 63-67.

Tanielian, C., Mechin, R., Seghrouchni, R., and Schweitzer, C. (2000). Mechanistic and kinetic aspects of photosensitization in the presence of oxygen. Photochem. Photobiol. 71, 12-19.

Tavares, A., Carvalho, C. M., Faustino, M. A., Neves, M. G., Tomé, J. P., Tomé, A. C., Cavaleiro, J. A. Cunha, A., Gomes, N. C., Alves, E., and Almeida, A. (2010). Antimicrobial photodynamic therapy: study of bacterial recovery viability and potential development of resistance after treatment. Mar. Drugs 8, 91-105.

Tedeschi, M., Varano, M., Schiano Lomoriello, D., Scassa, C., and Parisi, V. (2007). Photodynamic therapy outcomes in a case of macular choroidal neovascularization secondary to Candida endophthalmitis. Eur. J. Ophthalmol. 17, 124-127.

Tegos, G., Anbe, M., Yang, C., Demidova, T. N., Satti, M., Mroz, P., Janjua, S., Gad, F., and Hamblin, M. R. (2006). Protease-stable polycationic photosensitizer conjugates between polyethyleneimine and chlorin(e6) for broad-spectrum antimicrobial photoinactivation. Antimicrob. Agents Chemother. 50, 1402-1410.

Tegos, G., and Hamblin, M. R. (2006). Phenothiazinium antimicrobial photosensitizers are substrates of bacterial multidrug resistance pumps. Antimicrob. Agents Chemother. 50, 196-203.

Tegos, G., Stermitz, F. R., Lomovskaya, O., and Lewis, K. (2002). Multidrug pump inhibitors uncover remarkable activity of plant antimicrobials. Antimicrob. Agents Chemother. 46 3133-3141.

Tegos, G. P., Demidova, T. N., ArcilaLopez, D., Lee, H., Wharton, T., Gali, H., and Hamblin, M. R. (2005). Cationic fullerenes are effective and selective antimicrobial photosensitizers. Chem. Biol. 12, 11271135.

Teichert, M., Jones, J. W., Usacheva, M. N., and Biel, M. A. (2002). Treatment of oral candidiasis with methylene blue-mediated photodynamic therapy in an immunodeficient murine model. Oral Surg. Oral Med. Oral Pathol. Oral Radiol. Endod. 93, 155-160.

Tsai, T., Yang, Y. T., Wang, T. H., Chien, H. F., and Chen, C. T. (2009). Improved photodynamic inactivation of Grampositive bacteria using hematoporphyrin encapsulated in liposomes and micelles. Lasers Surg. Med. 41, 316-322.

Tubby, S., Wilson, M., and Nair, S. P. (2009). Inactivation of staphylococcal virulence factors using a light-activated antimicrobial agent. BMC Microbiol. 9, 211. doi:10.1186/1471-2180-9-211

Valko, M., Morris, H., and Cronin, M. T. (2005). Metals, toxicity and oxidative stress. Curr. Med. Chem. 12, 1161-1208.

Vermout, S., Tabart, J., Baldo, A., Mathy, A., Losson, B., and Mignon, B. (2008). Pathogenesis of dermatophytosis. Mycopathologia 166, 267-275.

Vilella, F., Herrero, E., Torres, J., and De La Torre-Ruiz, M. A. (2005). Pkcl and the upstream elements of the cell wall integrity pathway in Saccharomyces cerevisiae, Rom2 and Mlt1, are required for cellular responses to oxide stress. J. Biol. Chem. 280, 9149-9159.
Wainwright, M., Byrne, M. N. and Gattrell, M. A. (2006) Phenothiazinium-based photobactericidal materials. J. Photochem. Photobiol. B Biol. 84, 227-230.

Xavier, J. (2011). Social interaction in synthetic and natural microbial communities Mol. Syst. Biol. 7, 483.

Zolfaghari, P., Packer, S., Singer, M., Nair, S. P., Bennett, J., Street, C., and Wilson, M. (2009). In vivo killing of Staphylococcus aureus using a light-activated antimicrobial agent. BMC Microbiol. 9, 27. doi:10.1186/1471-2180-9-2

Conflict of Interest Statement: The authors declare that the research was conducted in the absence of any commercial or financial relationships that could be construed as a potential conflict of interest.

Received: 15 January 2012; paper pending published: 03 February 2012; accepted: 13 March 2012; published online: 10 April 2012.

Citation: Dai T, Fuchs BB, Coleman JJ, Prates RA, Astrakas C, St. Denis TG, Ribeiro MS, Mylonakis E, Hamblin MR and Tegos GP (2012) Concepts and principles of photodynamic therapy as an alternative antifungal discovery platform. Front. Microbio. 3:120. doi: 10.3389/fmicb.2012.00120

This article was submitted to Frontiers in Fungi and Their Interactions, a specialty of Frontiers in Microbiology.

Copyright (c) 2012 Dai, Fuchs, Coleman, Prates, Astrakas, St. Denis, Ribeiro, Mylonakis, Hamblin and Tegos. This is an open-access article distributed under the terms of the Creative Commons Attribution Non Commercial License, which permits non-commercial use, distribution, and reproduction in other forums, provided the original authors and source are credited. 